SOILS AND FOUNDATIONS Vol. 33, No. 1, 133-154, Mar. 1993

Japanese Society of Soil Mechanics and Foundation Engineering

\title{
LIQUEFACTION-INDUCED GROUND DAMAGE IN DAGUPAN IN THE JULY 16, 1990 LUZON EARTHQUAKE
}

\author{
KenjI Ishihara ${ }^{\mathrm{i})}$, Alex, A. ACACIo ${ }^{\mathrm{ii})}$ and Ikuo Towhata ${ }^{\mathrm{iii})}$
}

\begin{abstract}
Geotechnical aspects of the ground damage caused by widespread occurrence of liquefaction at the time of the 1990 Luzon, Philippines earthquake are highlighted by examining the geomorphological regime and boring data obtained in the city area of Dagupan. The comparison of old and present locations of the river courses indicates that the liquefaction in the city of Dagupan had taken place in two geomorphologically different areas: namely, the terrain of naturally buried old river channels and the area of point bar deposits. Although impossible to distinguish soil profile characteristics between these two types of terrains, the common feature is that there exists a surface layer composed of unliquefiable silty soils, underlain by sand deposits which are loose enough to provoke liquefaction. As a result of simple analysis of liquefaction, it was shown that the upper part of this sand deposits developed liquefaction, leading to the disastrous consequences in the city of Dagupan. By compiling a number of SPT data and the data of Swedish cone penetration tests, an attempt was made to clarify the relationship between the thickness of unliquefiable surface layer and that of the underlying liquefied layer which can or can not bring about surface manifestation of liquefaction, accompanied by disastrous damage on the ground surface. Lastly, the lateral spreads of the ground near the riverside were analyzed by considering the soil profiles established by the Swedish cone tests. The residual strength determined by back-calculation at three typical cross sections indicated a general coincidence with those estimated previously for other data sets.
\end{abstract}

Key words: case history, earthquake, liquefaction, penetration test (IGC: C3/D7)

\section{INTRODUCTION}

Liquefaction of the ground and associated lateral spreads towards terrains of lower relief have been recognized as major causes of destruction to structures and installations during recent earthquakes. It is well known that in the Loma Prieta earthquake of 1989 a large part of the damage to houses and public facilities in the reclaimed lands is attributed to the occurrence of liquefaction (Seed et al., 1991). In the more recent earthquake in Iran in 1990, the liquefaction in the fluvial deposits along the Caspian sea was a major cause of the damage to private dwellings and aqueduct systems for irrigation (Ishihara et al., 1992).

i) Professor of Civil Engineering, University of Tokyo, Bunkyo-ku, Tokyo 113.

ii) Associate Professor of Civil Engineering, University of Phillipines.

iii) Associate Professor of Civil Engineering, University of Tokyo.

Manuscript was received for review on February 27, 1992.

Written discussions on this paper should be submitted before October 1, 1993 to the Japanese Society of Soil Mechanics and Foundation Engineering, Sugayama Bldg. 4 F, Kanda Awaji-cho 2-23, Chiyoda-ku, Tokyo 101, Japan. Upon request the closing date may be extended one month. 
In the most recent earthquake of April 1991 in Costa Rica, the ground damage due to liquefaction is known to have caused serious destruction to long-distance highway fills, bridges and oil refinery facilities located in the plain area along the Calibian coast. It is well known that the Luzon earthquake in 1991 in Philippines also has brought about disastrous damage particularly in the area of city of Dagupan where liquefaction developed extensively (Tokimatsu et al., 1991). Rounds of field reconnaissance surveys were conducted for investigating the ground damage and subsurface soil conditions in the affected area. The results of the investigation and some related considerations will be described in the following pages of this paper.

\section{LUZON EARTHQUAKE OF JULY 16, 1990}

A destructive earthquake occurred on July 16, 1990 in the middle of Luzon Island about

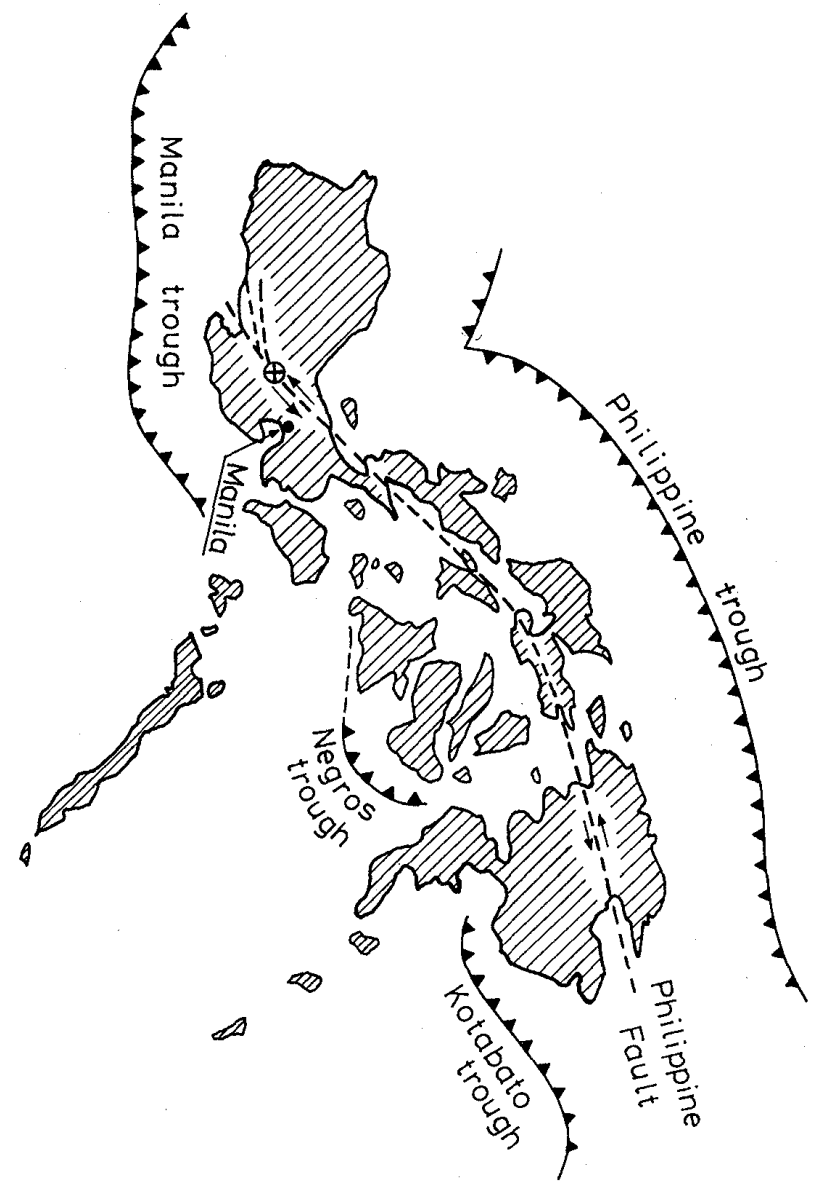

Fig. 1. Map of the Philippines Archipelago
$110 \mathrm{~km}$ north of Manila, Philippines (Fig. 1). Its magnitude, $M=7.8$, placed this event among the greatest to have occurred in the Philippine Archipelago in recent decades. The earthquake was accompanied by a slip along a $110 \mathrm{~km}-$ long segment of the Philippine fault that ruptured the Earth's crust to a depth of about $25 \mathrm{~km}$, as shown in Fig. 2. The ruptured segment is located in the northern-most edge of the $1200 \mathrm{~km}$-long Philippine fault extending northerly from Mindanao Island and veering northwestward in the middle of the Archipelago. The ground rupture appeared on the surface at the southern-most end near Dingalan and extended to the north terminating in the mountain east of Baguio. The rupture on the fault was left-lateral type producing a horizontal displacement of the order of 3-6 $\mathrm{m}$ in the segment north of Rizal and of the order of $2-3 \mathrm{~m}$ in the southern segment. The vertical offsets differed significantly from one place to another and there was no coherent pattern indicating uplifting or sub-

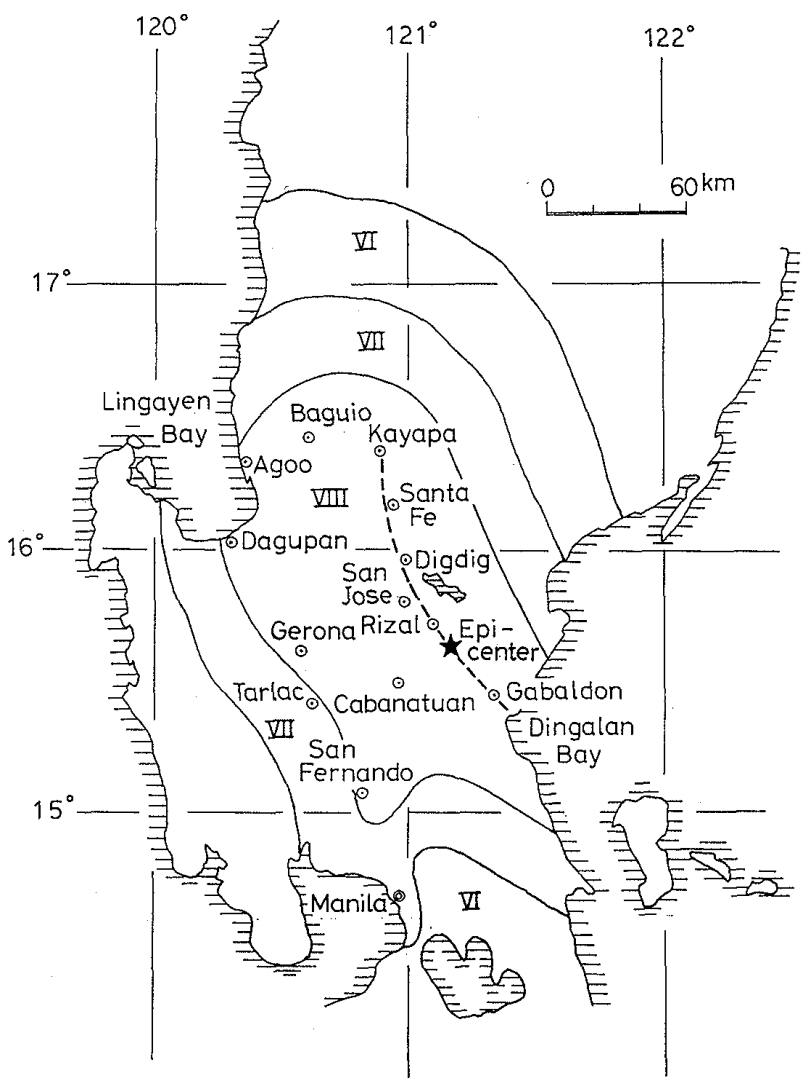

Fig. 2. Intensity distribution of the earthquake 
sidence of the land on either side.

The earthquake shook a widespread area in most of Luzon Island and the Mindro Islands. Unfortunately no instrumental records of the ground shaking were obtained during the main shock, but from the records registered abroad and based on the accounts of local witnesses, it is purported that there were at least two large shocks which occurred in sequence within 20 seconds of each other.

In the absence of any records on the motions, an effort was made by the reconnaissance team of the Japan Society of Civil Engineers (1991) to roughly estimate the magnitude of accelerations in the city area of Baguio on the basis of observed performances of rigid objects such as concrete fences or benches. The ratios of width to height of unaffected objects in this area were compared to those affected by the quake such as overturning or tilting. The outcome of the simple analysis as above indicated that the threshold value of the width-to-height ratio differentiating between conditions of overturning and non-overturning of the rigid objects was approximately 0.4 . Thus, the intensity of shaking in the city area of Baguio was inferred to have been of the order of $400 \mathrm{gal}$ in terms of the horizontal acceleration during the main shaking of the Luzon earthquake.

Intensity of seismic shaking is generally evaluated based on observations of earthquake effects on human body and structures, and further on destruction of the ground surface particularly in high intensity range. One of the most frequently used yardsticks is what is called the modified Mercalli scale (MMS). The intensity of shaking in the epicentral area in terms of MMS is shown in Fig. 2, where it may be seen that the shaking was the strongest in the belt zone in the vicinity of the surface fault and that the zone of intensity scale VIII encompassed a wide area from Agoo and Baguio in the north extending to Cabanatuan and San Fernando in the south.

The Philippine Archipelago has experienced a number of destructive earthquakes in the historic time. Fig. 3 shows the distribution of large earthquakes with a magnitude in excess

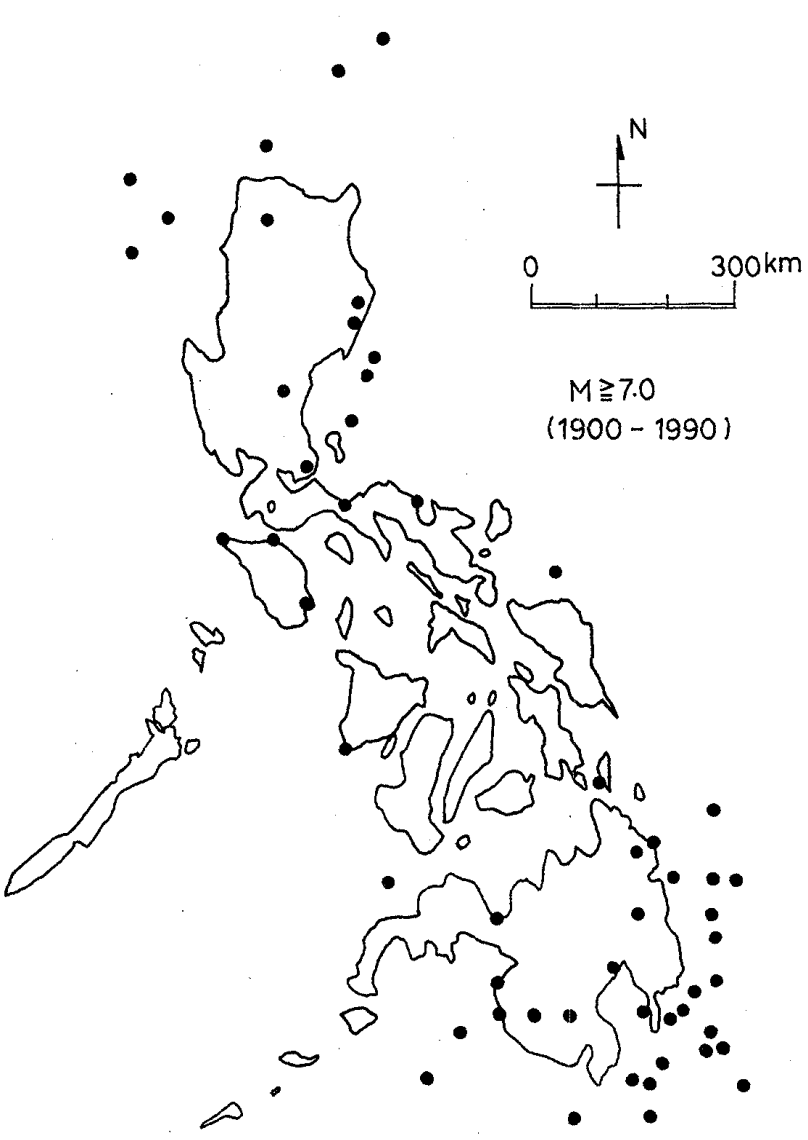

Fig. 3. Distribution of major earthquakes

of 7 which rocked the Archipelago in the 20th century. It may be seen that most of the large earthquakes occurred over the areas of north Luzon and southeast of the Mindanao Islands.

\section{GENERAL FEATURE OF DAMAGED AREAS}

The regions most seriously affected by the Luzon earthquake were the mountain area in the neighborhood of the city of Baguio and the vast expanse of alluvial lowlands in the Central Plain which is a northwest trending depression, bounded on the west by the Zambales Mountains and on the east by the Cordillera Central Range and Sierra Madre Mountains. The city of Dagupan located in the lowlands south of the Lingayen gulf was the area that was most severely damaged by the liquefaction due to the earthquake. The liquefaction-induced damage was observed in 


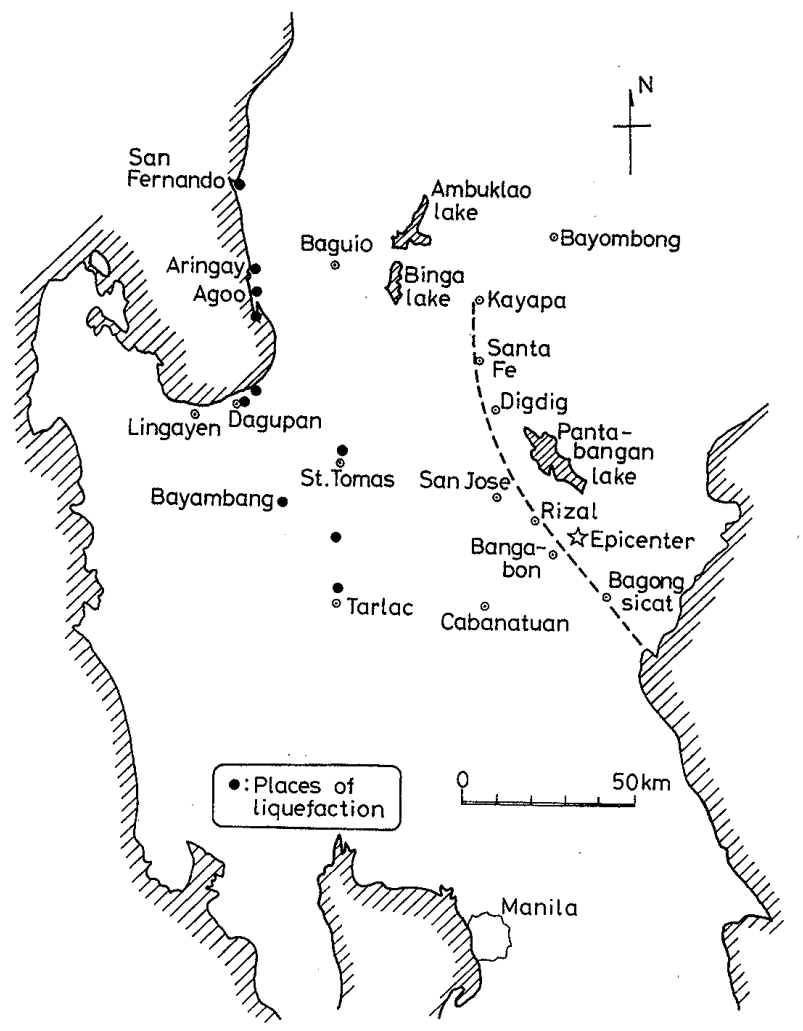

Fig. 4. Places of liquefaction

widespread areas as well from San Fernando in the north to the city of Tarlac in the south as indicated in Fig. 4.

\section{Baguio City}

The city of Baguio is a mountain community developed over sloping terrain area with an altitude of about $1500 \mathrm{~m}$, surrounded by mountain ranges. Annual precipitation amounts to $3500 \mathrm{~mm}$ with most of the downpour concentrated in the rainy season between July and October. In the city of Baguio, catastrophic features of the damage were collapse of modern multi-storey buildings and a large number of casualties buried in the rubble. Most of the structural damage was to reinforced concrete framed buildings 4 to 10 storeys tall. The damage involved complete collapse or flattening of these buildings. It is noteworthy that damage was least to private dwellings and shopping houses comprised of wooden-framed masonry structures.

\section{Dagupan}

The city of Dagupan is located in the northern-most rim of the vast expanse of alluvium in the Central Plain. The city is situated at the eastern margin of the delta created by Agno river (Figs. 5 and 6). The area along the Lingayen Bay is lowland of deltaic origin and multiple series of abandoned beach-barriers are still existent behind the current shoreline (Fig. 7). The near-shore area is purported to have been covered by thick forests of mangrove and nipa palm trees before early settlers began to live. Later, migrants started to establish many water-girt villages living on fishery operating in artificially-made fish ponds where fingerlings are stocked and algae is cultured. It is told that at the end of 16th century, villages were resettled into compact communities and converted into a town which was later named Dagupan. The geological regime of the area of Dagupan is shown in Fig. 5. and the complex meandering

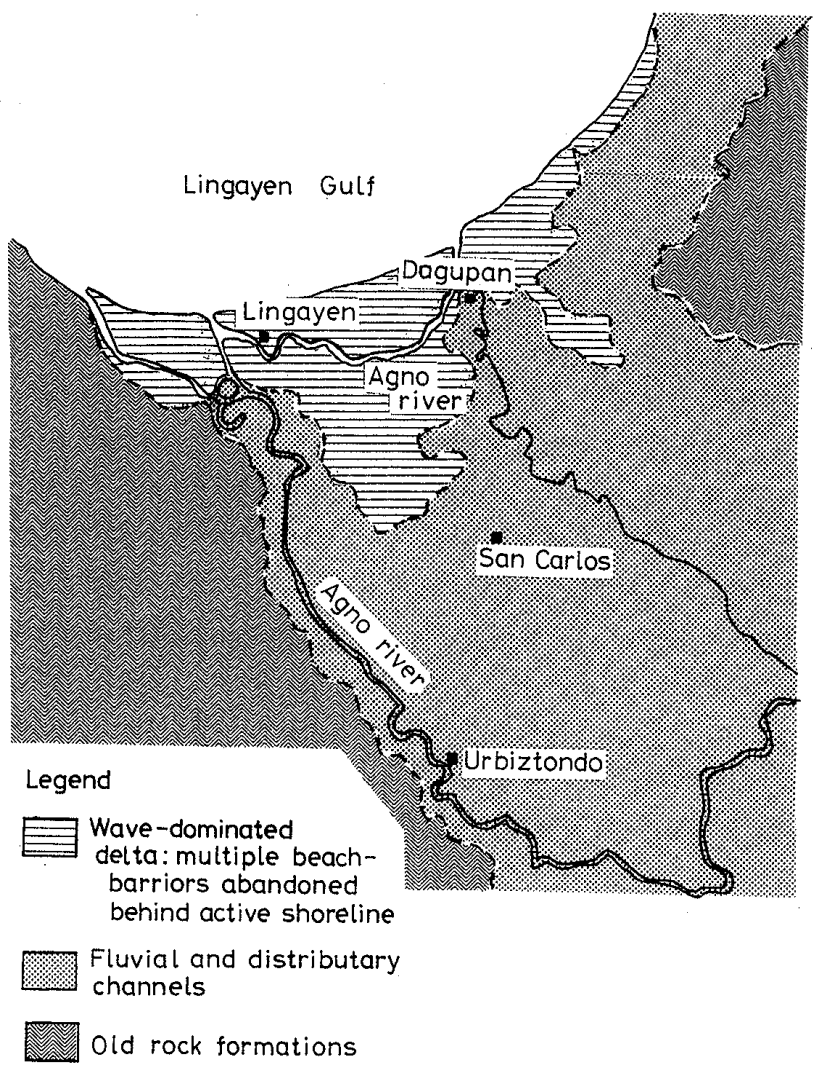

Fig. 5. Geological regime of the affected region (After Punongbayan and Torres) 


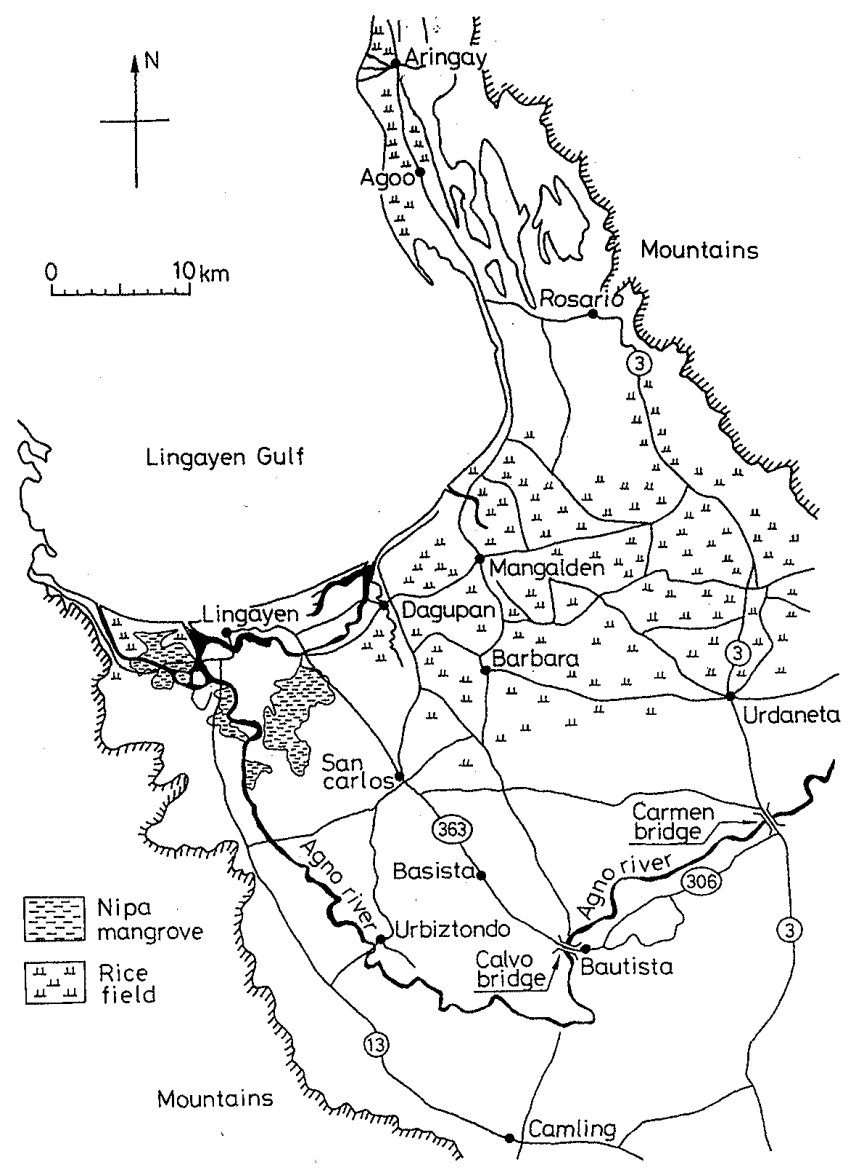

pattern of streams and river channels in its vicinity is shown in Fig. 8, where it may be seen that Dagupan city had developed over the deltaic lowlands where the Pantal river joins the main course of the Agno river.

It is purported that the center of the city had developed in the western part since 16 th century, but as the area became more and more populated, the low-lying terrain in the vicinity made up of backswamps or depressed grounds was reclaimed to provide enough landspace for the development of the township.

Fig. 6. Topographical map of the affected region

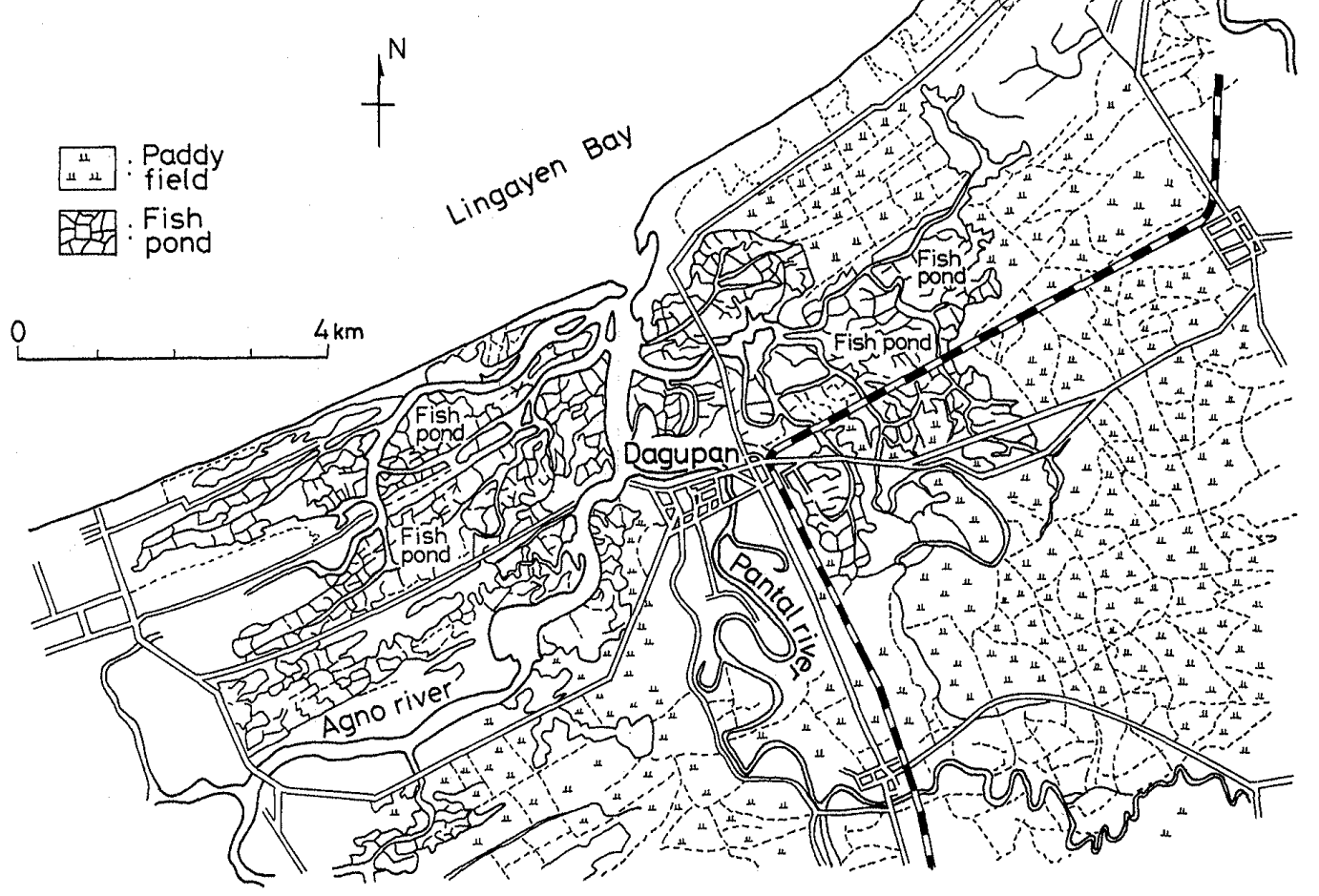

Fig. 7. The area of Dagupan near the Lingayen Gulf 


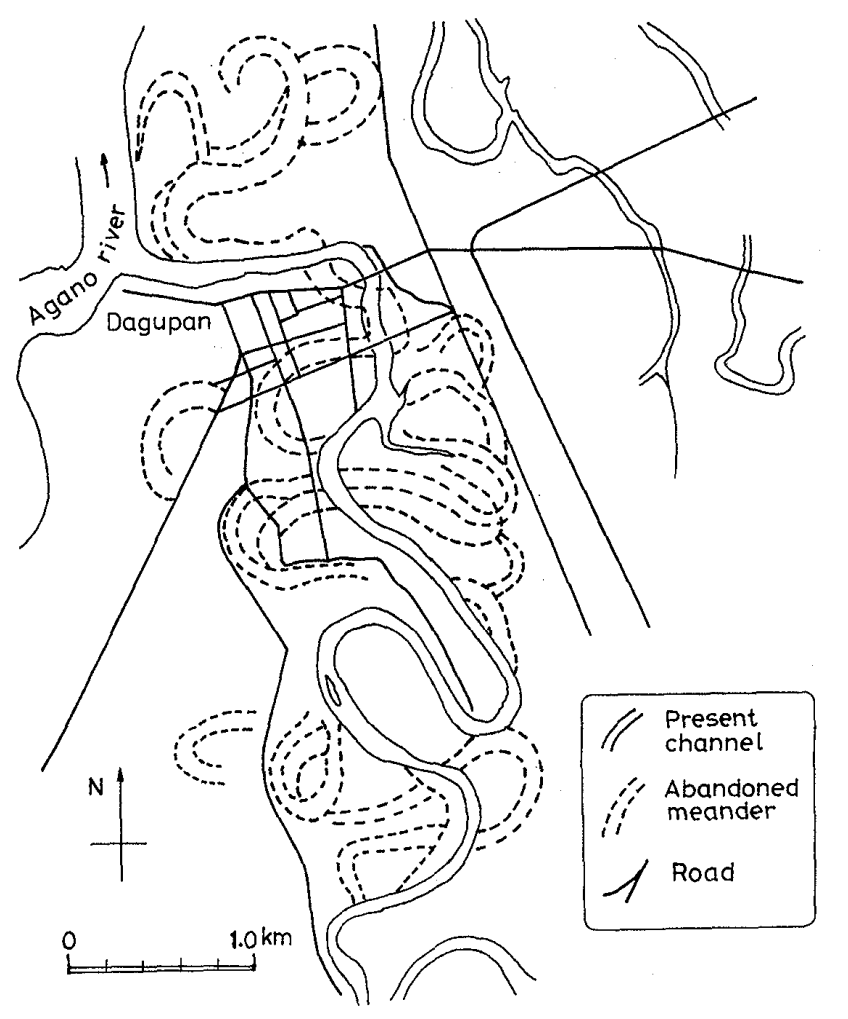

Fig. 8. Meandering patterns of old and present river channels (After Punongpayan and Torres)

\section{LIQUEFACTION IN DAGUPAN CITY}

\section{(1) Features of Damage Due to Liquefaction}

The city of Dagupan was severely devastated by the extensive liquefaction which occurred in the sandy deposits prevailing in the city area along the Pantal river. Physical evidences of liquefaction such as sand boiling and lateral flow of the ground were seen everywhere in the city. Fig. 9 shows the area where apparent signs of liquefaction were observed during the 1990 July earthquake. Along the main streets many buildings 2 to 10 storeys tall settled more than $1.0 \mathrm{~m}$ and the settlement was often accompanied by severe tilting. Fig. 10 shows buckling of a buried pipeline in the sideway along a main street in the city. It may be seen that the street was inundated with sand-laden water which spurted through broken pavement slabs as a result of liquefaction of underlying sand deposits. Fig. 11 shows a 3-storey tall reinforced concrete building at a street corner which settled about $1 \mathrm{~m}$ and tipped by about 5 degrees. The

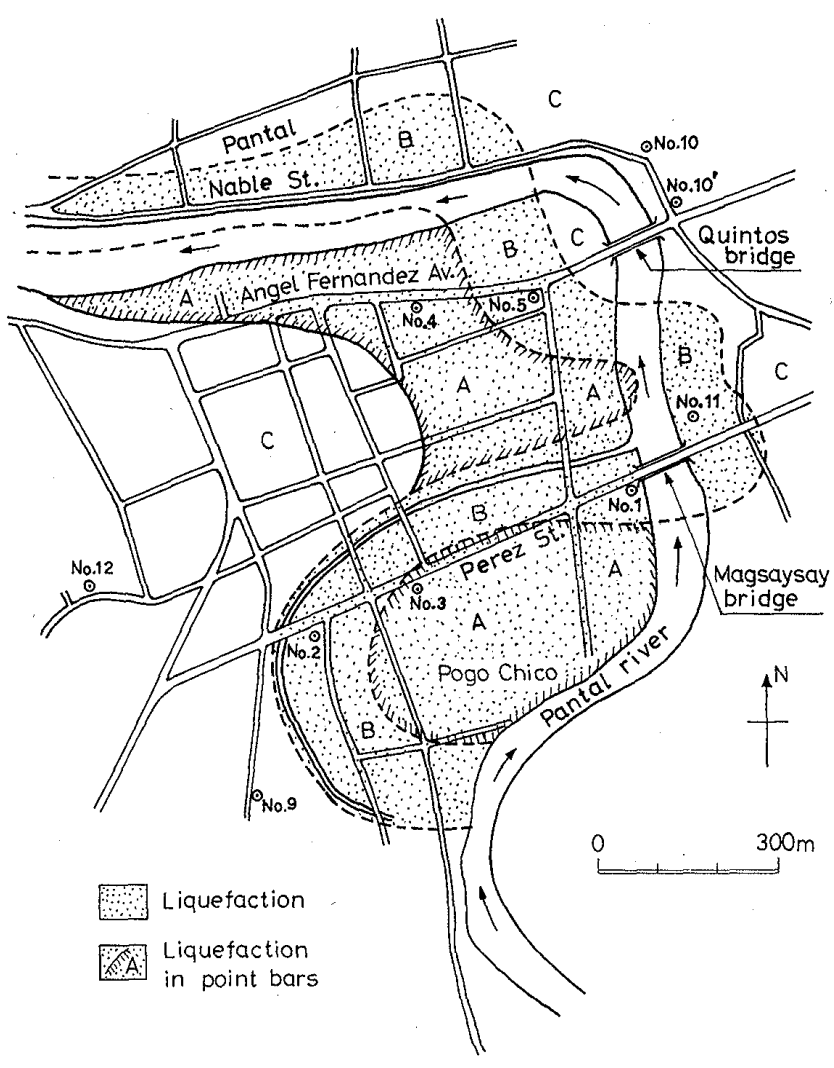

Fig. 9. City area of Dagupan affected by liquefaction

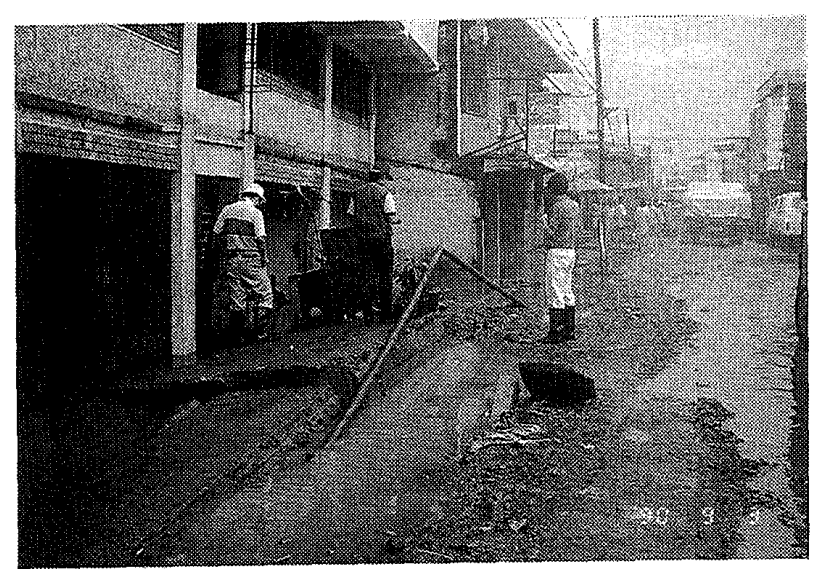

Fig. 10. Buckling of a buried pipeline

Magsaysay bridge crossing the Pantal river collapsed as a result of excessive sinking of piers as shown in Fig. 12. Fig. 13 shows features of this bridge prior to and after the earthquake. As indicated in Fig. 13(a), this bridge 144 meters long was comprised of 8 simply supported reinforced concrete girders resting on piers supported by concrete piles about $10 \mathrm{~m}$ 


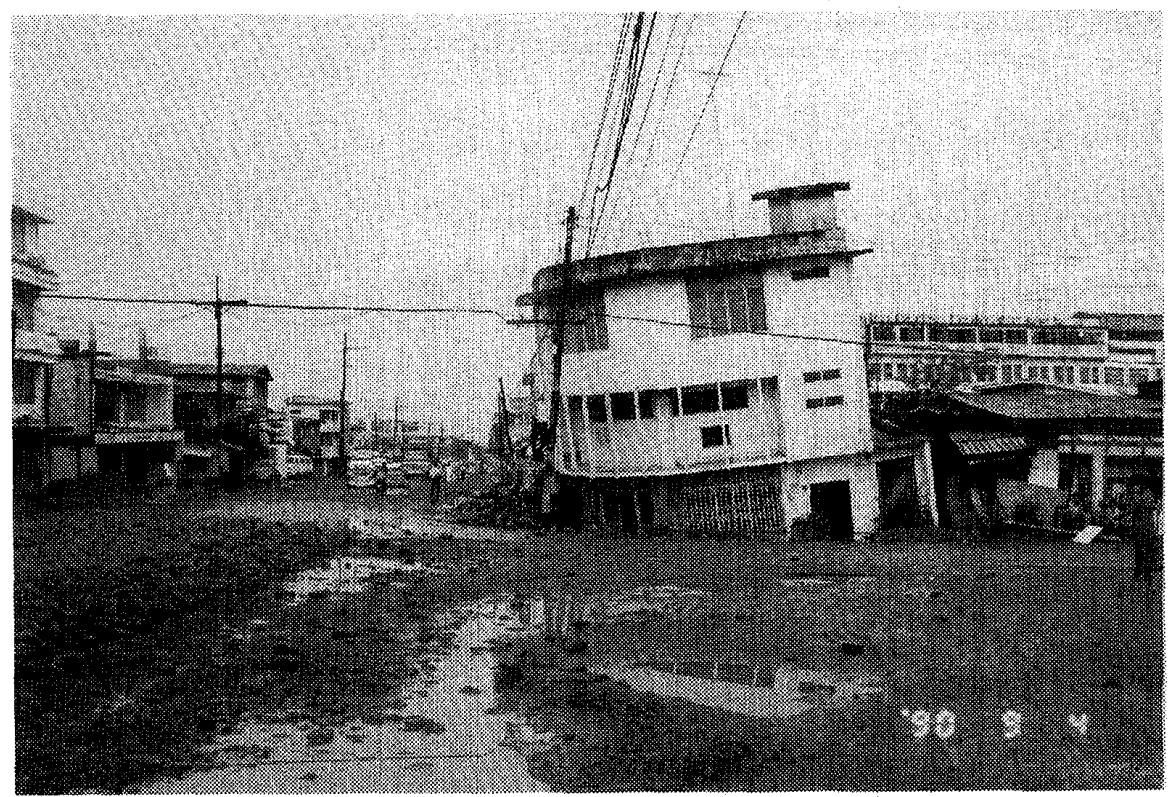

Fig. 11. Tilting and sinking of a building at Perez Street

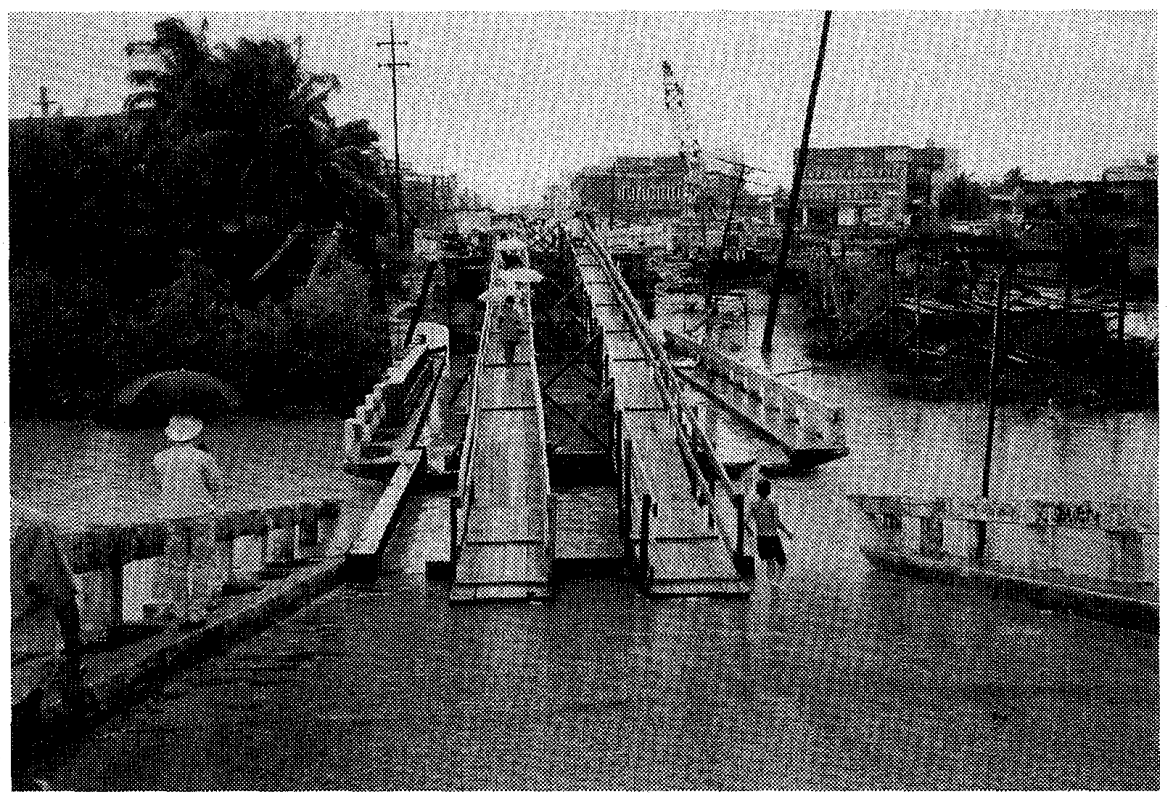

Fig. 12. Collapse of Magsaysay bridge

in length. The first and second piers from the right bank moved toward the river channel due to the lateral spread of the river bank and the third pier sank about $2 \mathrm{~m}$ due to loss of bearing capacity of the liquefied riverbed deposit.

On the right bank of the Pantal river near the Magsaysay bridge, the liquefaction was accompanied by a lateral flow of the ground towards the river by an amount of as large as about $5 \mathrm{~m}$ and as a result a 5 -storey reinforced concrete building with a radio tower settled about $2 \mathrm{~m}$ and tipped by 3 degrees. The feature of the lateral spread is observed through the change of the cross sectional line of the river bottom which was surveyed after the earthquake as shown in Fig. 13(b).

The lateral spreading of the ground towards the river occurred at many places where liquefaction was manifested along the Pantal 
(a) Before the earthquake
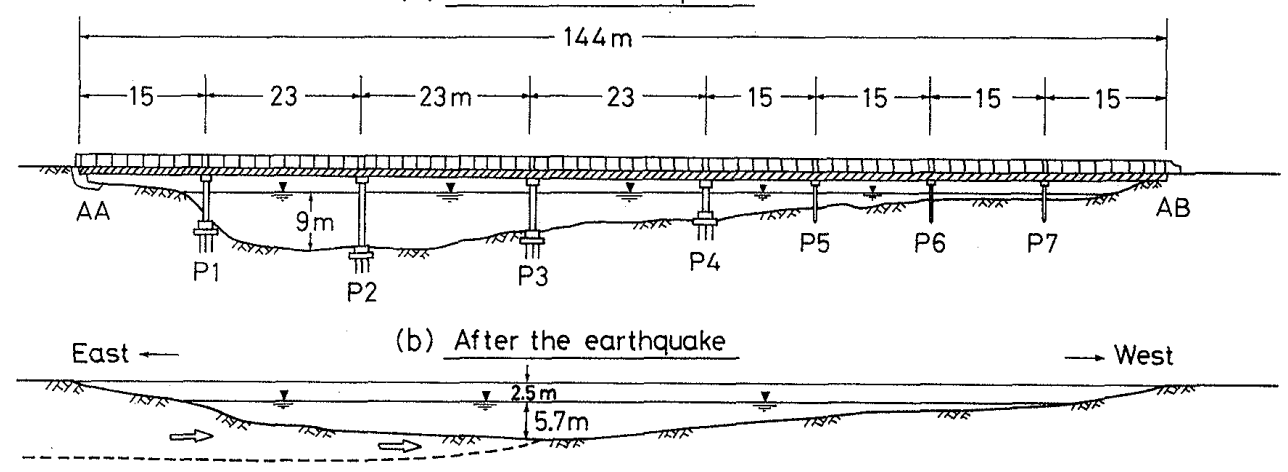

(c) After the earthquake

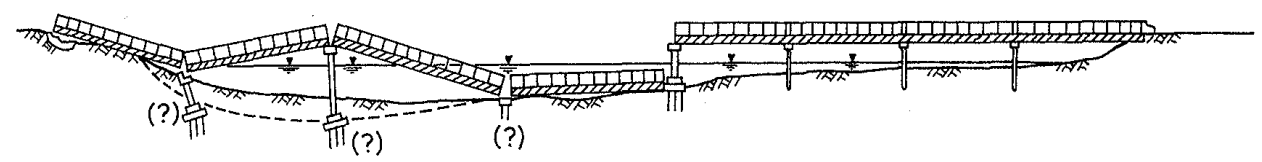

Fig. 13. Sideviews of Magsaysay bridge before and after the earthquake

river. The locations and approximate values of lateral displacements are indicated in Fig. 14 , where it can be clearly seen that practically all the areas behind the present river bank had suffered a lateral deformation of the order of 1 to $6 \mathrm{~m}$. For instance, the road on the Nable street in the district of Pantal moved by 1 to 3 $\mathrm{m}$ towards the river as a consequence of liquefaction developed in the sandy deposits. The right bank of the Pantal river in the vicinity of the Magsaysay bridge is underlain by sandy deposits and consequently developed extensive liquefaction accompanied by a lateral flow amounting to about $5 \mathrm{~m}$.

\section{(2) Geological Aspects of Zones of Liquefac- tion}

As described above, the city area of Dagupan had developed over the lowlands in the lower reaches of the Pantal river which has a complexly meandering pattern as shown in Fig. 8. The shift of the river courses is purported to have taken place naturally for a long geological era, and therefore the abandoned portion of the river channel indicated in Fig. 8 is not man-made fills, but was created probably by transport of sediments during flooding and inundation. It is generally believed with good reason that the area of old river channels is composed of loose deposits of silts and

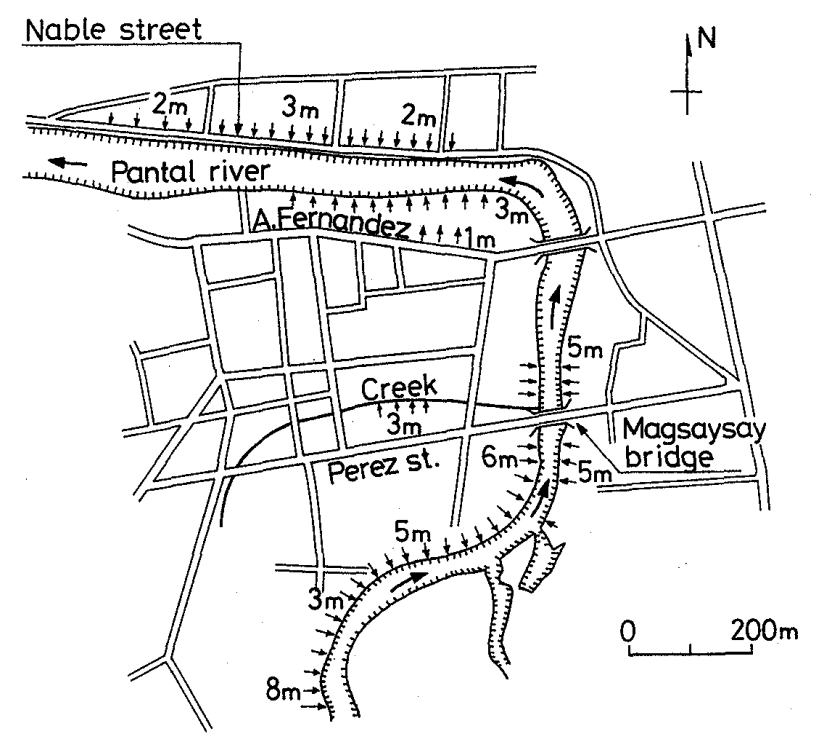

Fig. 14. Lateral flow along the river side (After Wakamatsu et al., 1991)

sands, whether it is of natural sediments or man-made fills, and thus susceptible to liquefaction during earthquakes. Judging from the depth of current river channel, the naturally-formed fills appears to extend down to a depth of about 5 to $10 \mathrm{~m}$.

In the geomorphological considerations, it is well known that the terrain of point bar develops through the action of entrenchment by river currents during flooding, whereby accompanied by sequences of sedimentation of 
sands and silts therebehind. Since the materials are deposited under slowly moving waters, the sediments are generally loose and thus susceptible to liquefaction during earthquakes. On the contrary, the area on the opposite side subjected to entrenchment is generally composed of somewhat dense deposits of older era and immune to the development of liquefaction. Viewed in this manner, the area of flood plains such as in Dagupan can be divided into three different sections.

1) Terrain of abandoned old river courses consisting of loose deposits of silts and sands.

2) Terrain of point bars where deposits of sands and silts are loose.

3) Terrain behind channel levees composed of dense deposits of sands and silts in old era.

Based on the above classification and with reference to the channel pattern shown in Fig. 8 , the city area of Dagupan may be split into three sections as denoted by A, B and C in Fig. 9. The area $A$ may be regarded as part of the point bar and accordingly suffered destructive damage due to liquefaction. The area Pogo Chico south of Perez Street is purported to have been Nipa swamps until the middle of this century, but filled afterwards by silts or sands to a thickness of 1 to 2 meters. It is instructive to notice that the heavily liquefied area, B, coincides almost exactly with the area where the old river channel used to exist probably until hundreds of years ago. The area $C$ was free from destruction due to liquefaction, because of the dense deposits being existent behind the channel levees.

\section{SUBSURFACE SOIL CONDITIONS IN DAGUPAN}

\section{(1) Site Investigation by Standard Penetra- tion Tests}

Since the earthquake of July 16, 1990, soil conditions in the urban area of Dagupan have been investigated extensively by the city authority. The investigation involved the conduct of the standard penetration tests (SPT) at several key locations and laboratory tests on disturbed soil samples to determine physical properties of soils. The locations of SPT are in- dicated in Fig. 9 and the soil profile data obtained at two representative sites are shown in Fig. 15. In this figure, the point No. 3 is a soil profile along Perez Street and the point No. 5 represents the site along Angel Fernandez Avenue.

When the original data on SPT were examined in the light of Japanese data, it was discovered that the $N$-values obtained in Dagupan are significantly larger as compared to the blow count values from sites in Japan where liquefaction was pronounced during recent earthquakes. It was further found out
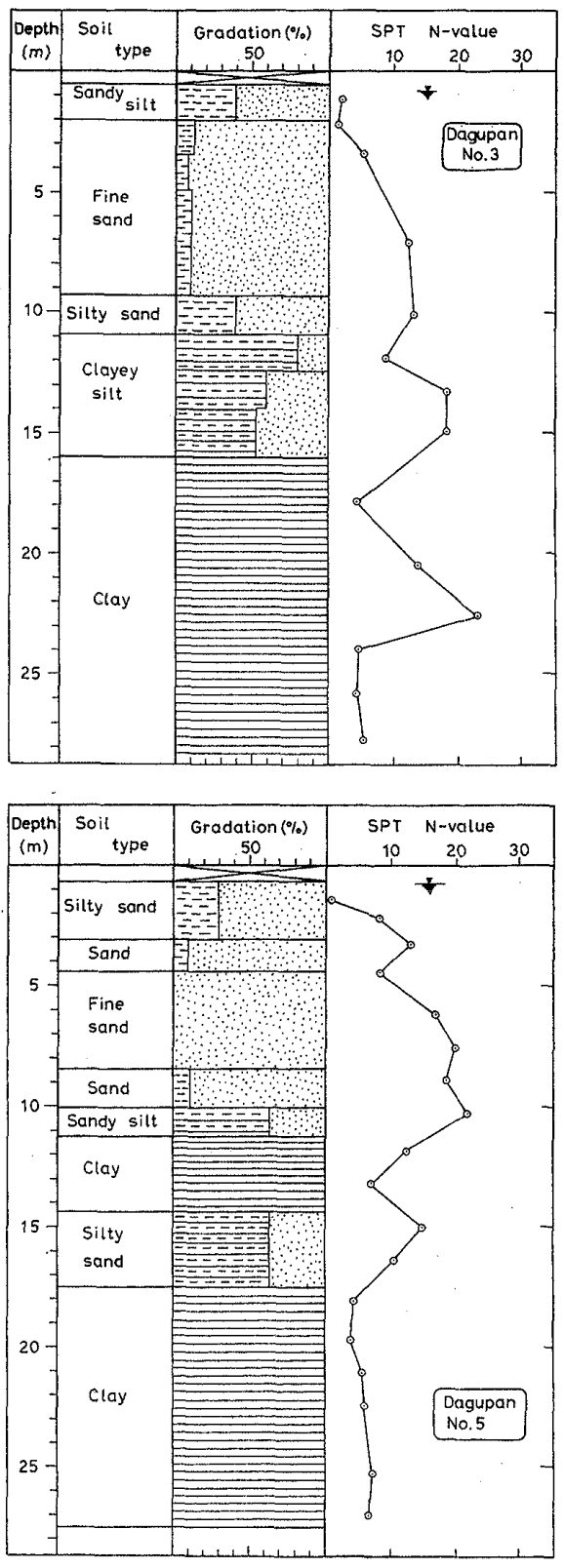

Fig. 15. Boring data in Dagupan 
that the practice of SPT in Dagupan employs a winch machine to operate the hammer hitting. In conducting the SPT, a $63.5 \mathrm{~kg}$ hammer is lifted by a wire cable which is rolled many times around a $30 \mathrm{~cm}$-in-diameter drum. When dropping the hammer, the wire cable is released to move down by suddenly disengaging a brake in the winch machine. Since the release of the wire cable involves several rotations of the drum, it was suspected that some amount of hitting energy was lost due to moment inertia of the drum and mechanical friction during the operation of hammer dropping.

In view of the essential need for knowing the degree of energy loss, a series of comparative tests was recently conducted on SPT in Dagupan by employing two different methods of hammer dropping. One was what is called the trip monkey method in which the hammer is directly dropped from a hanger named Tombi through a height of $75 \mathrm{~cm}$. The other was by means of the winch machine which has been used by the city office of Dagupan. Yoshimi and Tokimatsu (1983) conducted a set of comparative tests on SPT by using the trip monkey hammer dropping on one hand and the cathead-rope method with two turns of rope on the other hand. The results of their comparative tests indicated that, for the range of small to medium $N$-values less than about 25 both methods yielded the same value of blow count. Thus, the $N$-values obtained in the comparative tests in Dagupan using the trip monkey method was considered to be equal to many data of the SPT blow count values which have been obtained in Japan by means of the cathead-rope method with two turns of rope. The reason why the trip monkey method was used in Dagupan was that it was very simple to operate and there was no need to prepare devices such as a cathead and rope.

The comparative tests were conducted at a site near the boring point No. 11 just downstream of the Magsaysay bridge on the right bank of the Pantal river as shown in Fig. 9. The comparative standard penetration tests were performed in two bored holes $3 \mathrm{~m}$ apart from each other, one using the trip monkey method and the other by means of the winch method. The results of the comparative tests are presented in Fig. 16 where it can be seen that the near-surface soils were so soft that the SPT hammer penetrated by its own weight and yielded zero blow count down to a depth of $5 \mathrm{~m}$. Below this depth, the $N$-value obtained by the winch machine was about twice the value of blow counts obtained by the trip monkey method except for the $N$-value at a depth of $8 \mathrm{~m}$ where the soil was identified to be different between the two holes. For quan-

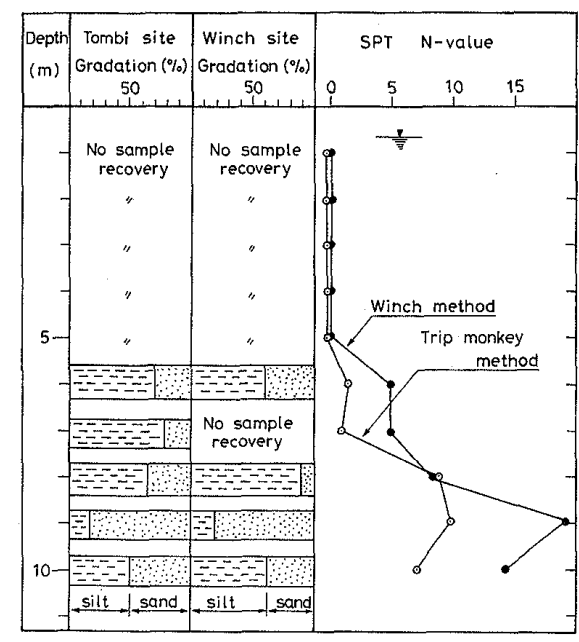

Fig. 16. Results of the comparative tests by SPT

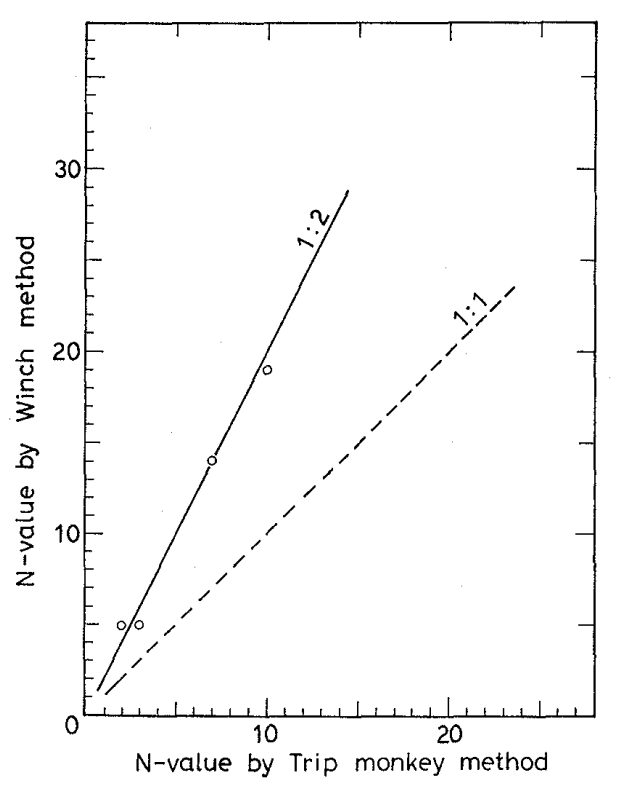

Fig. 17. Comparison of SPT-data 
titative comparison purposes, the $N$-value obtained by the winch method is plotted in Fig. 17 versus the corresponding $N$-value obtained at the same depth by means of the catheadrope procedure. Because of the fines content of the soil at the depth of $8 \mathrm{~m}$ being significantly different between the two holes, the $N$ values at that depth are not included in the comparison chart of Fig. 17. It can be seen in Fig. 17 that the $N$-value by means of the trip monkey method is half of the $N$-value obtained by the winch machine. Thus, it was decided to modify all the $N$-values offered by the city office so that they are consistent and comparable with the $N$-values obtained in Japan mostly by means of the trip monkey. The modification was made simply by taking a half of the $N$-values measured in Dagupan by the city office.

The results of SPT shown in Fig. 15 are those modified in the above manner. The soil profile data shown in Fig. 15 indicate commonly that there exist four distinct deposits of soils with different grain-size compositions. Near the surface to a depth of 2-3 m, there exists a layer of sandy silt or clayey silt with varying grain composition from one location to another. This soil deposit appears to be the dumped soils which were placed at respective sites when the swamplands or mangrove marshlands were reclaimed early in this century. The blow count values of the soils in this surface deposit ranges between 2 and 7 . The soils generally contain more than $40 \%$ fines and are to be regarded as the material having a great resistance to liquefaction. Thus, it would appear reasonable to assume that, although the reclaimed fills near the surface are soft or loose, they may not have developed liquefaction themselves during the Luzon earthquake of 1990. It should be noticed in passing that the ground water table is generally high in the city of Dagupan, being about 0.5 to $1.0 \mathrm{~m}$ below the ground surface. The soil profiles shown in Fig. 15 indicate also that beneath the surface mantle there exists a sandy layer with a thickness varying from $5 \mathrm{~m}$ to $12 \mathrm{~m}$. The blow count value of this sandy deposit is less than 15 in the upper half but it tends to increase even to a value beyond 30 in the lower half. (Fig. 18) It is presumed with good reasons that liquefaction had taken place in the upper part of this layer where the $N$-value is less than about 12 .

Underneath the sand layer there exists a clay or silt-rich deposit having a $N$-value varying between 10 and 30, as indicated in Fig. 18. This clayey layer appears to be of diluvial origin and accordingly possesses high stiffness.

Underlying the three distinct deposits as above is a thick layer of clay with medium to high stiffness as inferred from the $N$-value of the order of 10. This clay layer appears to be of diluvial origin and prevails in the widespread region surrounding Dagupan. According to the boring data at site No. 10' which was drilled to a deepest depth of $36 \mathrm{~m}$, this clay layer was found to terminate at a depth of $35 \mathrm{~m}$ underlain again by a deposit of silty sand. The soil profile at depths deeper than $36 \mathrm{~m}$ in Dagupan area is not known.

\section{SIMPLE ANALYSES OF LIQUEFACTION}

The magnitude of acceleration encountered in the Dagupan area during the earthquake is not known, but from the attenuation characteristics of the seismic motions relevant to this region, the maximum horizontal acceleration may be postulated to have been on the order of 200 gal. Assuming the ground water table to have been $1.0 \mathrm{~m}$ below the surface and using the SPT $N$-value in the empirical formulae by Japanese Bridge design code, the resistance of the sand deposits to liquefaction was estimated and compared against the external force due to the shaking during the earthquake. The details of analysis procedure for liquefaction is described elsewhere (Ishihara, 1985). As a result of the simple analyses, approximate depth and thickness of the liquefied zone were identified through the soil profile at each site of boring. The liquefied zone thus established is demonstrated in Fig. 18 in the form of cross-sectional diagrams which cut through two major streets in the city of Dagupan. The cross-sectional view along the Perez Street shown in Fig. 18(a) indicates that 


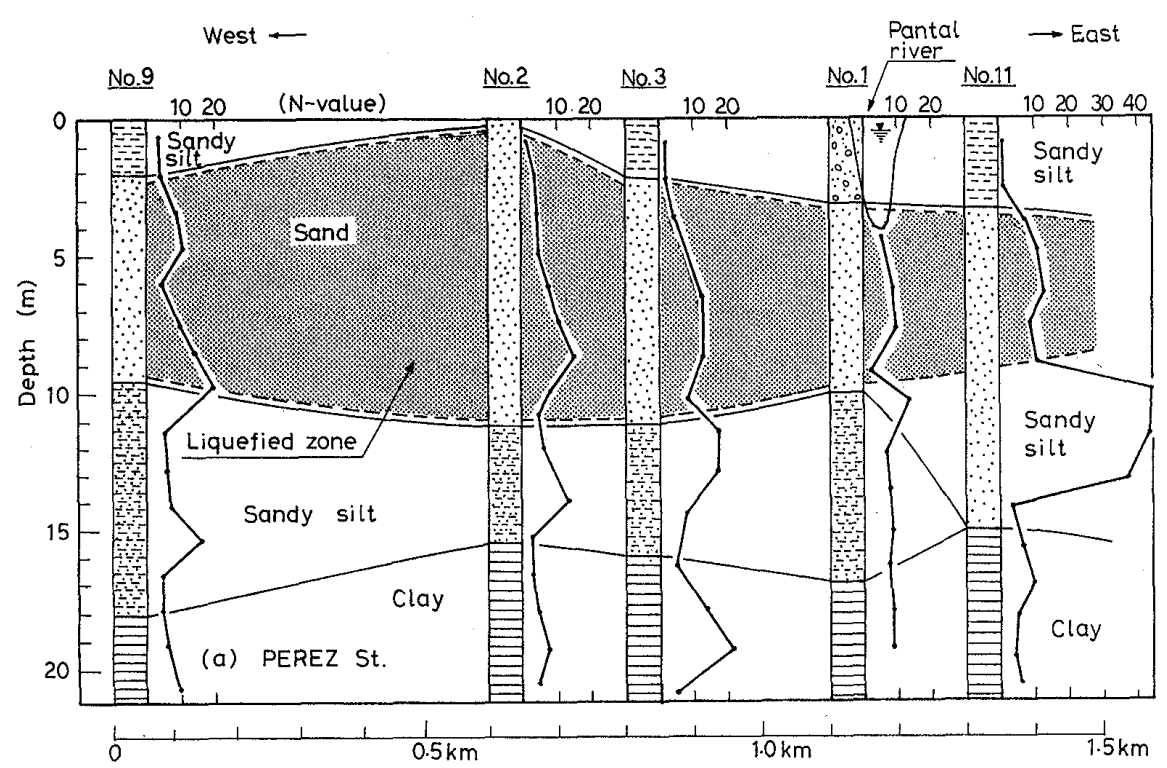

(a)

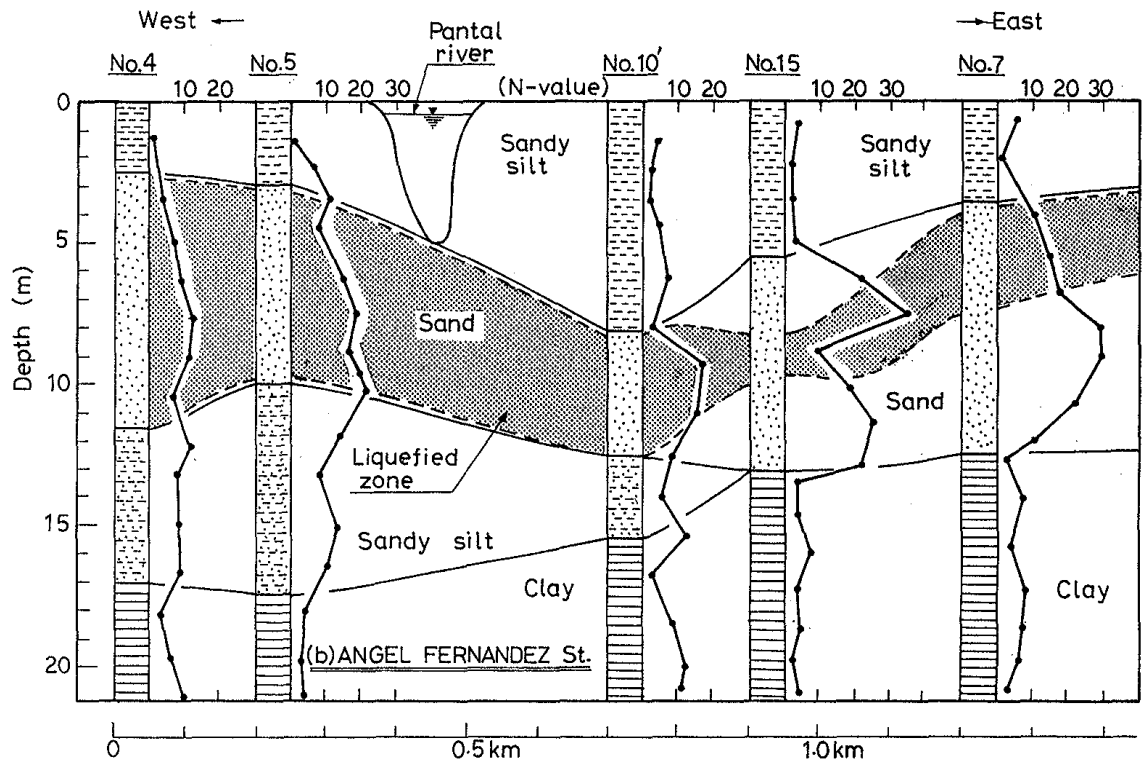

(b)

Fig. 18. Soil profiles along major streets

the liquefaction must have developed through the sandy deposit down to a depth of $10 \mathrm{~m}$, but its thickness tends to taper off towards the east. This tendency is more pronouncedly recognized in the cross sectional diagram shown in Fig. 18(b) which was obtained along the Angel Fernandez Street. It is noted in Fig. 18(b) that in the area east of the Pantal river, liquefaction appears to have developed only in a deep sand deposit and therefore its effects were not manifested over the ground surface.

\section{SITE INVESTIGATION BY SWEDISH CONE TESTS}

The Swedish cone penetration test consists of two operations. In the first place, a screwtype tip called screw point is penetrated by increasing stepwise the static load, Wsw, until it reaches a total of $100 \mathrm{~kg}$. Further penetration 
is carried out by manually rotating the screw rod while applying $100 \mathrm{~kg}$ of the static weight and the number of half-revolutions required for one meter of penetration, Nsw, is obtained. It is a usual practice to plot the two measures of penetration resistance, $W_{s} w$ and $N s w$, successively on a common coordinate, so that the overall picture of soil stiffness throughout the depth can be visualized at a glance. Thus, in the plot of the Swedish cone resistance shown in Fig. 20, zero point in the $N s w$-measure corresponds to $100 \mathrm{~kg}$ in terms of $W s w$-measure. One of the great advantages of the Swedish cone test over the usage of other sounding techniques such as SPT and
Dutch cone test is that the main part of the apparatus weighs only about $30 \mathrm{~kg}$, and can be transported even on board an airplane and operated manually in the field by manpower of three persons. In the present study, a reconnaissance team of Kisojiben Consultants Co. carried a set of test apparatus to Philippines except for the weight of $100 \mathrm{~kg}$. They prepared several plastic bags to fill in sand on the spot of penetration tests. The sand bags were hung on the top of screw rod of the Swedish cone to apply the static load. The test apparatus was presented and left afterwards to the University of Philippines and all the Swedish cone tests described in this paper were performed by the

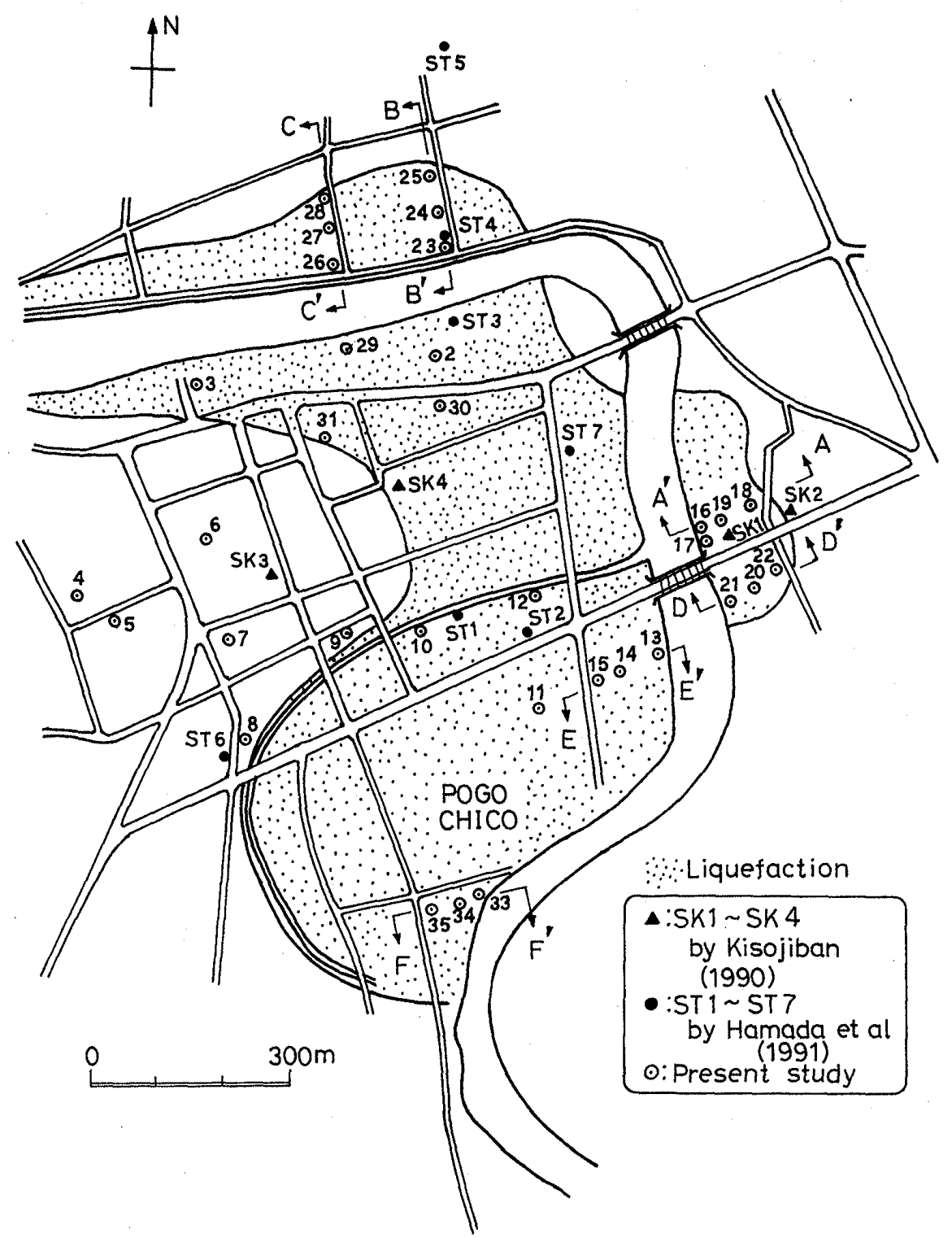

Fig. 19. Locations of Swedish cone tests 
use of this apparatus.

Individual locations where the Swedish cone tests were performed are shown in the map of
Fig. 19. Three groups of investigators have been involved in conducting the Swedish cone tests. The first group was a team of Kisojiban
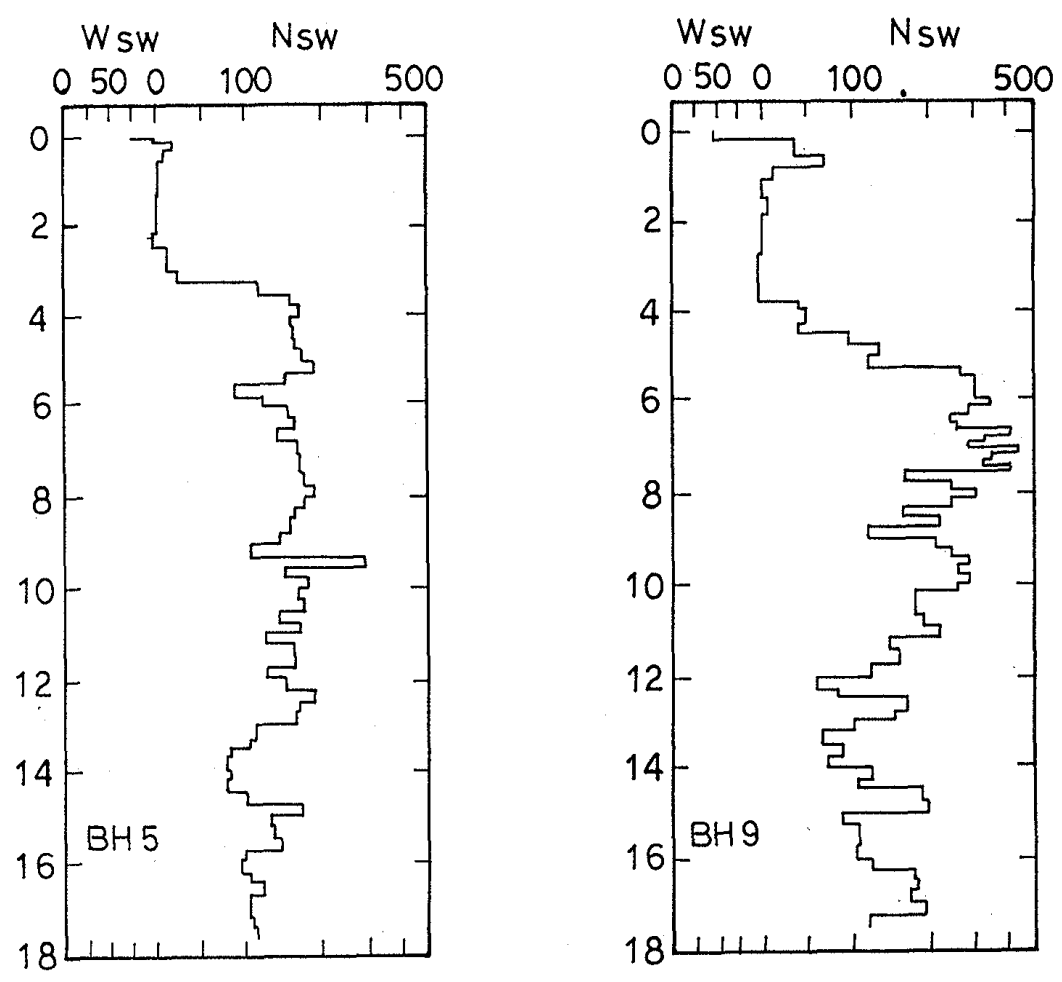

(Undamaged area)
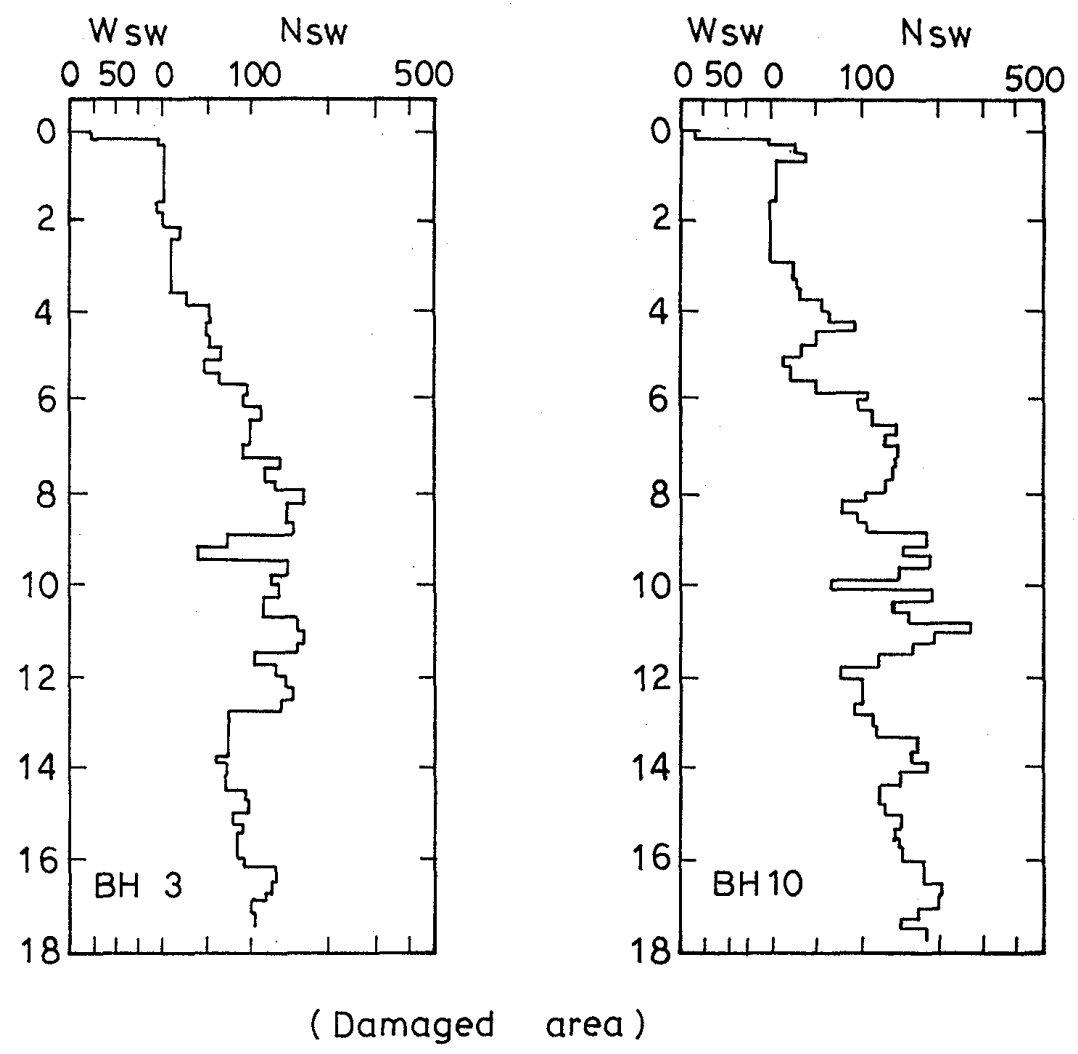

Fig. 20. Typical results of Swedish cone tests 
Consultants who investigated four sites as indicated in Fig. 19 about two months after the earthquake. A team of the Association for Development of Earthquake Prediction led by Professor M. Hamada conducted another series of Swedish cone tests at seven sites as shown in Fig. 19. The third series of the tests was carried out by the authors at 35 sites. Some of the test results showing the difference in soil profile between where liquefaction-induced damage did and did not occur are presented in Fig. 20. The results of the tests at sites $\mathrm{BH} 5$ and 9 are representative of the soil profiles at sites where evidences of liquefaction were not observed, whereas the soil profiles at sites $\mathrm{BH} 3$ and 10 are representative of those where clear signs of liquefaction were observed after the earthquake. It may be seen in Fig. 20 that there exists a surface layer to a depth of about $3 \mathrm{~m}$ where the resistance to penetration is low with $N s w=0$. In comparison to the soil profiles investigated by SPT, this surface layer is identified to be a deposit consisting of sandy silts or silts which are generally immune to liquefaction. The deposit underlying this surface layer is identified to consist mainly of sands with reference to the soil profiles established by SPT (Fig. 18). Comparison of two sets of the Swedish cone test data clearly indicates that the sand deposits at sites BH5 and BH9 are denser with $N s w$-values in excess of 150 , as compared to the $N s w$-values less than 100 at sites 3 and 10 where apparent signs of liquefaction were manifested on the ground surface. Thus, it may be conclusively mentioned that the difference in the ground behavior regarding whether the liquefaction-induced damage did or did not occur during the earthquake is attributed to the looseness or denseness of the sand deposits underlying the silty surface layer.

\section{EFFECTS OF AT-DEPTH LIQUEF ACTION}

It has been presumed that the occurrence of liquefaction itself at some depth within a soil profile is not necessarily related to the damage of installations founded on or near the ground surface. Only when the development of liquefaction is sufficiently extensive through the depth of a deposit and shallow enough in proximity to the ground surface, effects of liquefaction are manifested on the ground surface leading to sand boiling and ground fissuring accompanied by destruction to structures and facilities. To explore this aspect of the problem, the relationship between the thickness of unliquefiable layer, $H_{1}$, and the thickness of underlying liquefied deposit, $\mathrm{H}_{2}$, which may or may not give rise to the damage on the ground surface was sought by examining data of boring and sounding tests obtained in the city area of Dagupan and its surroundings.

\section{(1) SPT-Based Relationship}

When a sand-rich deposit exists near the surface such as those shown in Fig. 15, the depth of the ground water table was taken as the thickness, $H_{1}$, of the unliquefied surface layer. If a silty deposit is identified to exist near the surface, the thickness of this layer was chosen to be equal to $H_{1}$. With respect to the determination of underlying buried liquefied stratum, the sand deposit with SPT $N$-value less than 12 was considered to have developed liquefaction and its thickness was taken as being equal to $\mathrm{H}_{2}$. The threshold $\mathrm{N}$-value of 12 differentiating conditions of liquefaction and non-liquefaction was determined from the results of simple analyses as demonstrated in Fig. 18. Pairs of data on $H_{1}$ and $H_{2}$ compiled in the above manner are presented in Fig. 21 by plotting them in the abscissa and ordinate. The data from sites of known liquefaction damage are indicated by black circles and those from sites without damage are marked by white circles. Shown together in Fig. 21 is the boundary curve established previously by Ishihara (1985) on the basis of investigation on the area devastated by the shaking of order of 200 gal at the time of the 1985 NihonkaiChubu earthquake in Japan. It may be seen in Fig. 21 that the data points with known liquefaction damage fall mostly in the zone on the left of the boundary curve, providing added evidences of the appropriateness of the curve established before. 


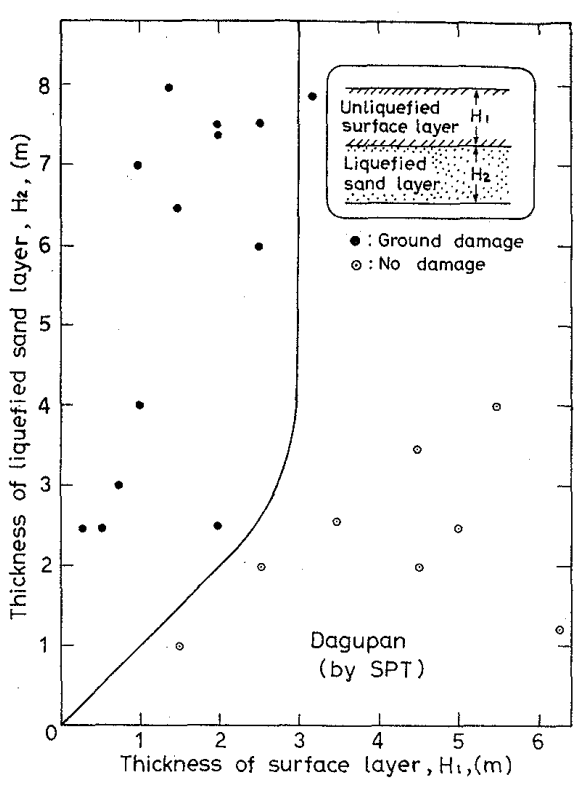

Fig. 21. Effects of unliquefiable surface crust upon the damage on the ground surface (by SPT)

\section{(2) Relationship Based on Swedish Cone Tests.}

As mentioned previously, a majority of data on the Swedish cone tests in the area of Dagupan showed a zone of low penetration resistance near the ground surface to a depth of about 1 to $5 \mathrm{~m}$, which was identified to be silt-rich deposit having a great resistance to liquefaction. On the other hand, scrutiny of many data on the Swedish cone tests conducted in Japan has shown that the deposits permitting static penetration to be done with the load $W s w$ less than $100 \mathrm{~kg}$ consists generally of fine-grained soils such as silt or clay. Thus, the near-surface deposits having a low penetration resistance with $W s w$-value less than $100 \mathrm{~kg}$ may be regarded, with good reasons, as the surface layer which is immune to liquefaction. Therefore, in examining the Swedish cone data in Dagupan, the depth of the surface layer with $W s w=100$ or $N s w=0$ was taken to be equal to the thickness of unliquefied surface layer $H_{1}$.

In the underlying sand deposits, the liquefaction has been identified to have taken place if the deposit is loose enough with a SPT $N$ value below 12 . This threshold value may be converted into an equivalent $N s w$-value in Swedish cone tests, if the following empirical

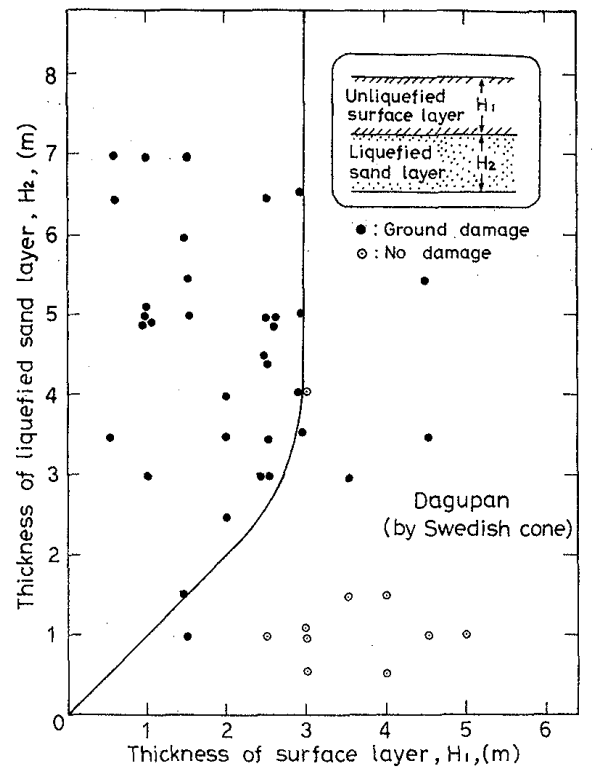

Fig. 22. Effects of unliquefiable surface crust upon the damage on the ground surface (by Swedish cone)

formula by Inada (1982) is used with $W s w=100$

$$
N=0.02 W s w+0.067 N s w .
$$

Introducing the threshold $N$-value of 12 , one obtains the equivalent $N s w$ of 150 . Thus, the thickness of the underlying liquefied layer at the sites of Swedish cone penetration tests was estimated based on this criterion. The pairs of data on $H_{1}$ and $H_{2}$ thus obtained for each of the test sites shown in Fig. 19 are plotted in Fig. 22 in the same manner as was done in Fig. 21. In Fig. 22, the same boundary curve as shown in Fig. 21 is also displayed. The four solid points on the right side of the boundary curve appear to be there because of the overestimate of the thickness of unliquefied surface layer which is difficult however to specify precisely based on the rough criterion as mentioned above. Except these points, it may be seen that the bounding curve as introduced above is fitted to a reasonable degree of accuracy for differentiating between conditions of liquefaction-induced damage and no damage.

\section{FLOW FAILURE IN THE RIVERSIDE}

One of the characteristic features of the damage caused by the liquefaction of the sand 
deposits in the city of Dagupan was massive movement of the ground along the bank of the Pantal river. Near the riverside area, small houses were seen torn apart and trees uprooted, perching on rugged sliding soil masses. In the area somewhat rearwards, open cracks and fissures were observed here and there on the ground surface in parallel to the river channel. The area of the ground destruction with diagnostic evidencesof lateral spread as above was observed to extend about 20 to $50 \mathrm{~m}$ backwards from the riverfront. Thus, the extent of the liquefied ground involved in the flow slide appears to be within the belt zone along the river bank having a width of 20 to $50 \mathrm{~m}$. The area behind this belt zone is considered to develop the type of liquefaction prevalent in the level ground condition free from the lateral deformation. Approximate amount of lateral deformation at the riverfront established by Wakamatsu et al. (1991) is indicated on the map in Fig. 14 with some modifications. In view of the fairly large amount of deformation being as much as $5 \mathrm{~m}$ and also judging from the disastrous features of associated ruins, it may be assumed with reasons that the major part of the lateral deformation had probably taken place as a result of flow-type slide. It has been argued in the previous paper (Ishihara et al., 1991) that the flow type failure could occur, for a prolonged period of time after the cessation of seismic shaking, in a sandy deposit when it is put in the steady-state of deformation after the onset of liquefaction. When the liquefied deposit is put into the steady-state and the flow type deformation sets in, the sand can mobilize only a small amount of resistance along the sliding surface which is called the residual strength or steady-state strength. Evaluation of the residual strength based on the backward analyses of actual failure cases have been attempted by Seed (1987) and Ishihara et al. (1990). For the flow failure along the bank of the Pantal river, an attempt was made by Ishihara et al. (1991) to assess the residual strength on the basis of the back-analysis by considering three cross sections, A-A', B-B' and $\mathrm{C}^{-} \mathrm{C}^{\prime}$ indicated in Fig. 19. There are three additional cross sections that are worthwhile

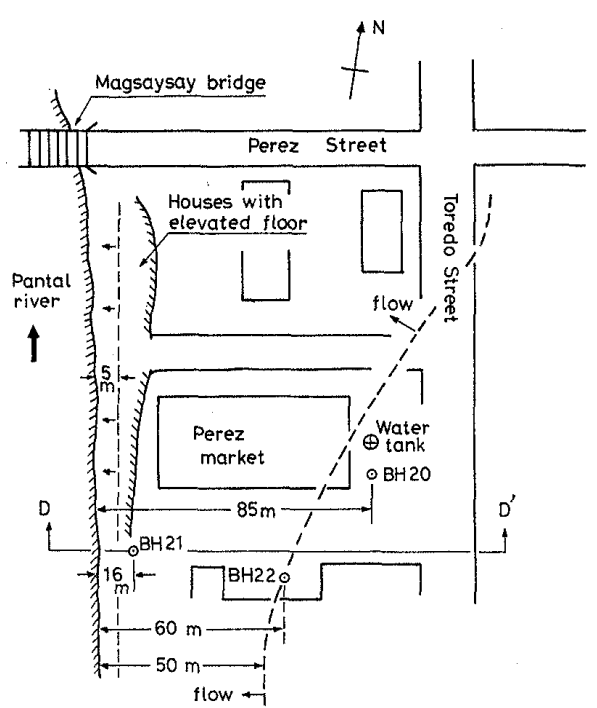

Fig. 23. Approximate sketch of the ground conditions around the area of cross section $D-D^{\prime}$

being analyzed for which the results of the analyses will be described in the following pages.

\section{(1) Right Bank Slide Upstream of Magsaysay Bridge}

The right bank of the Pantal river suffered a large lateral displacement of the order of $5 \mathrm{~m}$ near the site just upstream of Magsaysay bridge as indicated by $\mathrm{D}^{-\mathrm{D}^{\prime}}$ in Fig. 19. The somewhat detailed feature of the ground conditions is illustrated in a sketch shown in Fig. 23 , together with exact locations of penetration tests by means of the Swedish cone. The results of the penetration tests are displayed in Fig. 24 as a side view within the cross section D-D'. It may be assumed that the major deformation had taken place along the sliding plane developed at a depth of $4 \mathrm{~m}$. By allowing for the effects of surcharge of $P=30 \mathrm{kPa}$ due to the presence of a warehouse, a simple analysis was made, as illustrated in Fig. 25, to backcalculate the residual strength, $S u$, which must have been mobilized at the time of the sliding. The result of analysis showed a value of 4.5 $\mathrm{kPa}$ for the residual strength.

\section{(2) Left Bank Slide Upstream of Magsaysay Bridge}

The area on the left bank just upstream of Magsaysay bridge also suffered destructive 


\begin{tabular}{lllcc} 
& distance,$(\mathrm{m})$ \\
100,80, & 60, & 40 & 20, \\
\hline
\end{tabular}

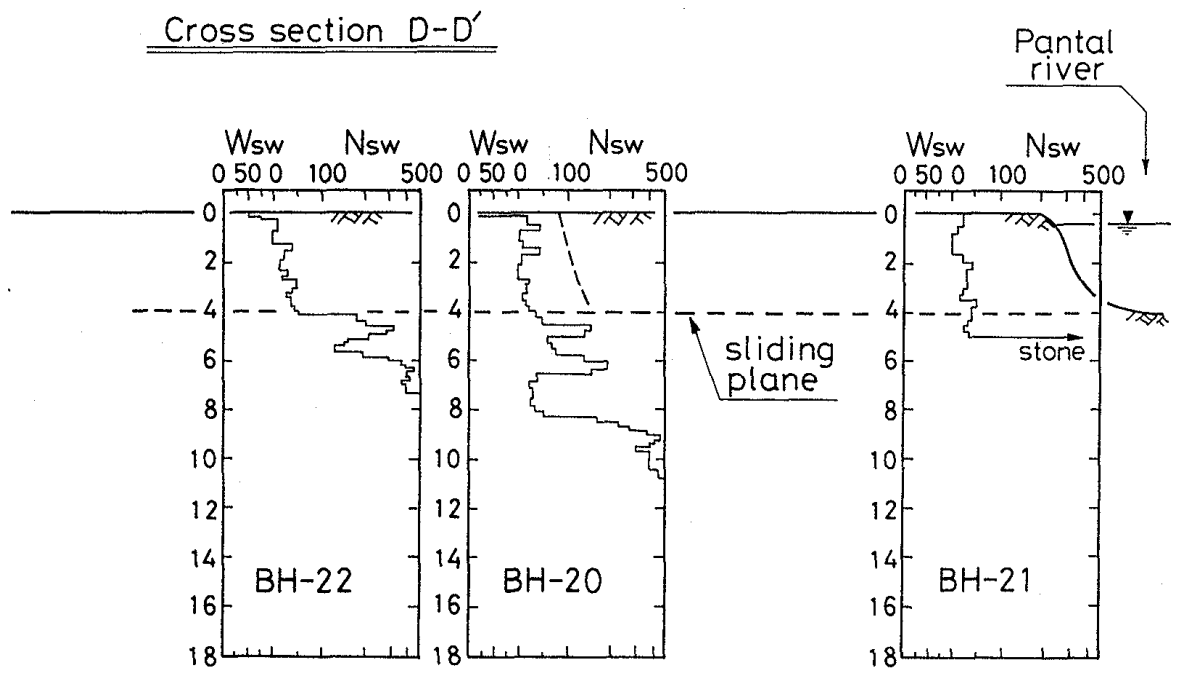

Fig. 24. Soil profile in cross section D-D'

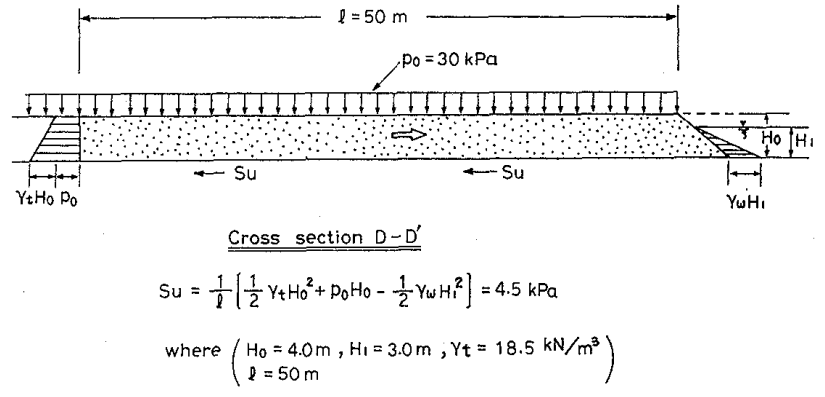

Fig. 25. Back-calculation scheme in cross section D-D

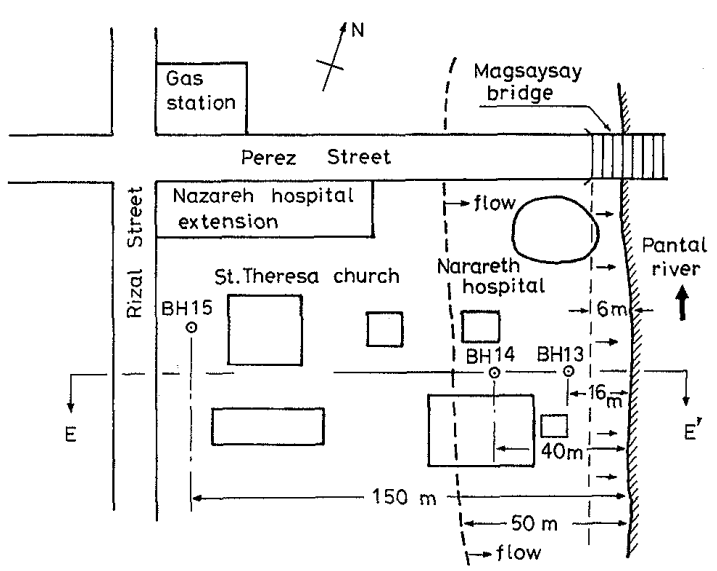

Fig. 26. Approximate sketch of the ground conditions around the area of cross section E-E'

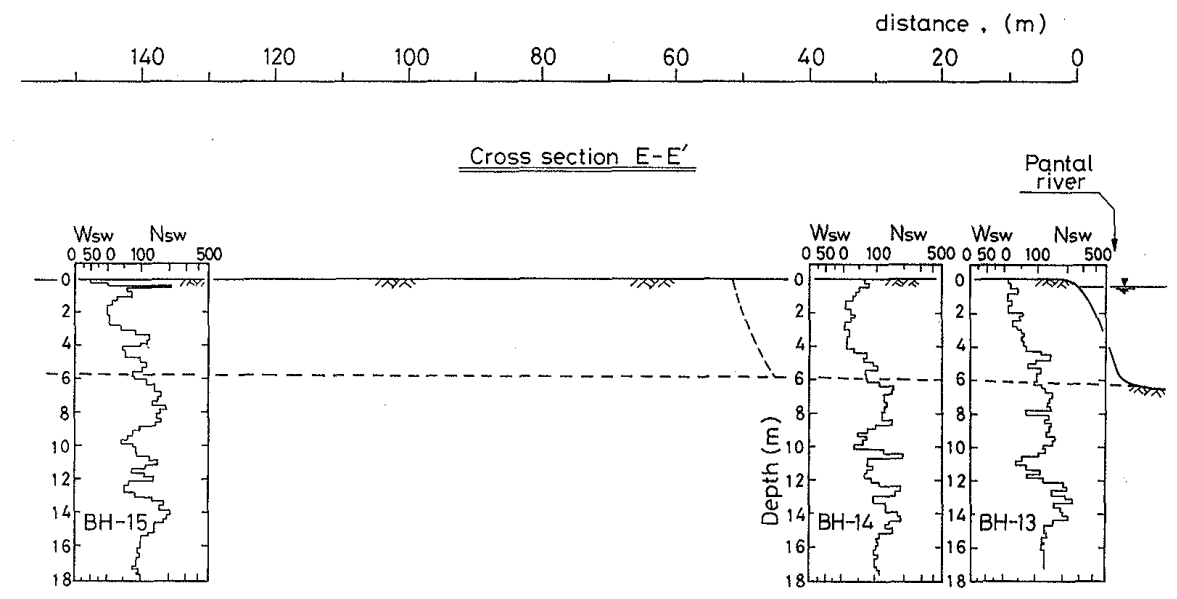

Fig. 27. Soil profile in cross section $\mathbf{E}-\mathbf{E}^{\prime}$ 
damage due to the lateral spreading of the ground towards the river. A large hospital building was tipped, torn apart, and drifted to the river. Numerous sand boils and open cracks were observed all over the ground surface. Detailed conditions of the ground disruption are described in Fig. 26, together with locations of Swedish cone penetration tests. The results of the cone tests are displayed in Fig. 27 as a side view across he cross section E$\mathrm{E}^{\prime}$. The lateral deformation appears to have occurred mainly along the sliding surface at a depth of $6 \mathrm{~m}$ within the riverside soil mass extending about $50 \mathrm{~m}$ inwards from the riverfront. The depth of the Pantal river is inferred to be about $6.0 \mathrm{~m}$ judging from the side view shown in Fig. 13. For the cross section, E-E', as established in Fig. 27, slope stability

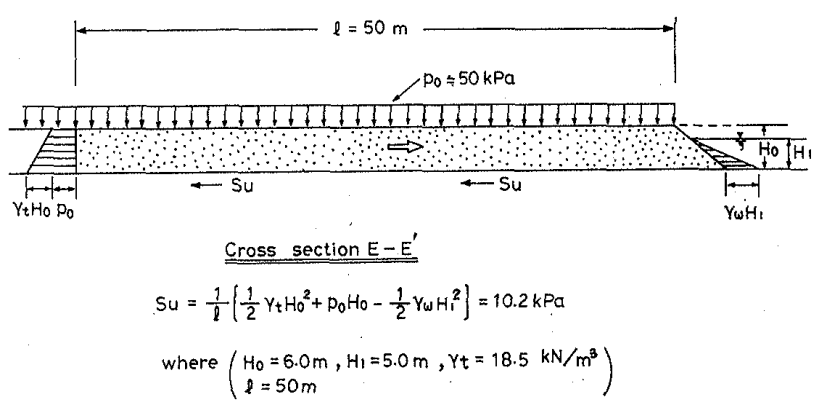

Fig. 28. Back-calculation scheme in cross section E-E' analysis was made to back-calculate the residual strength by allowing for the effects of a surcharge of $P=50 \mathrm{kPa}$ due to the presence of large buildings. The result of analysis as illustrated in Fig. 28 shows the residual strength of $S u=10.2 \mathrm{kPa}$.

\section{(3) Left Bank Slide at Pogo Chico}

In the southern part of the Dagupan city,

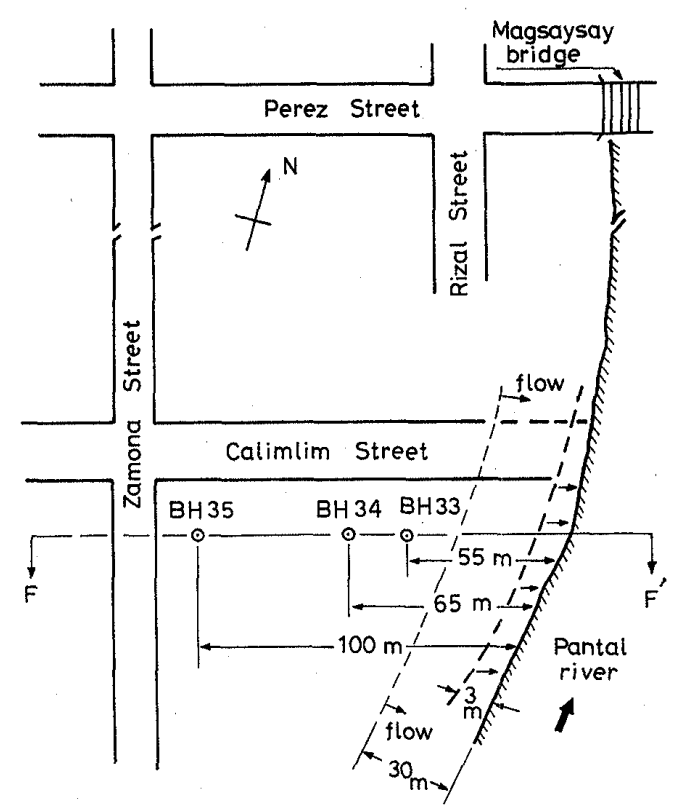

Fig. 29. Approximate sketch of the ground conditions around the area of cross section $F-F^{\prime}$

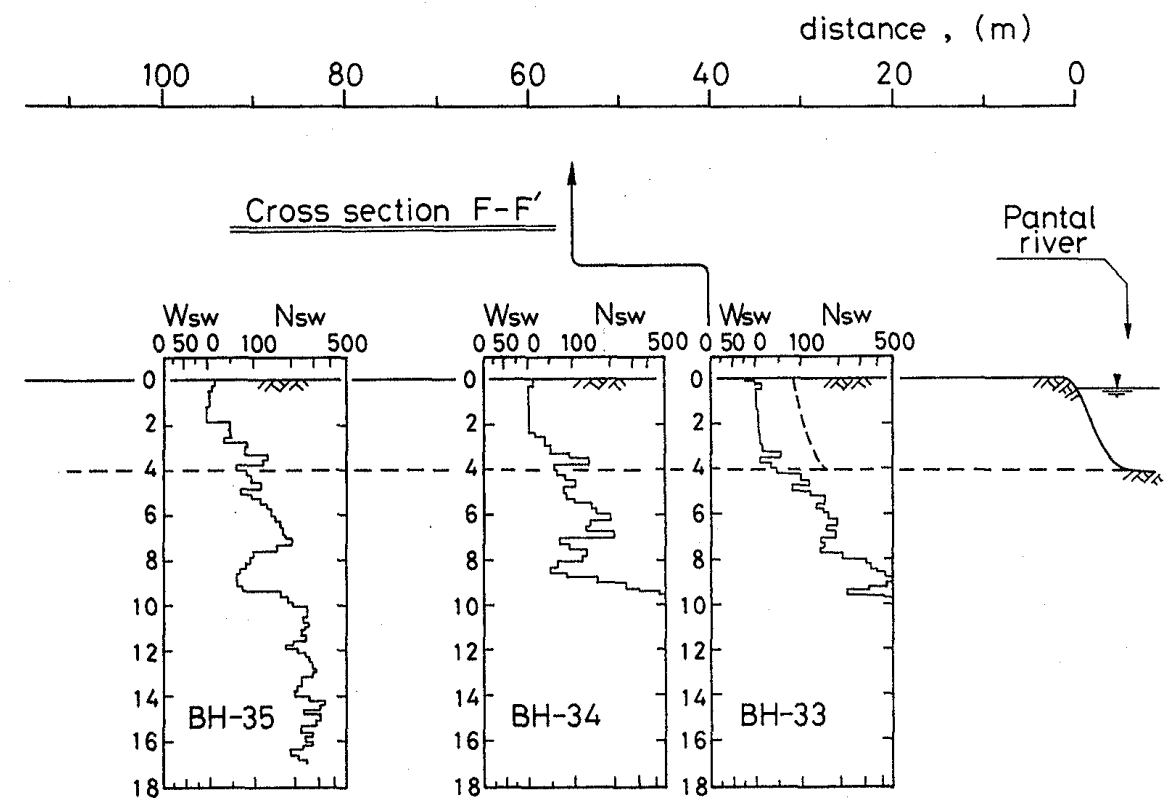

Fig. 30. Soil profile in cross section $F-F^{\prime}$ 


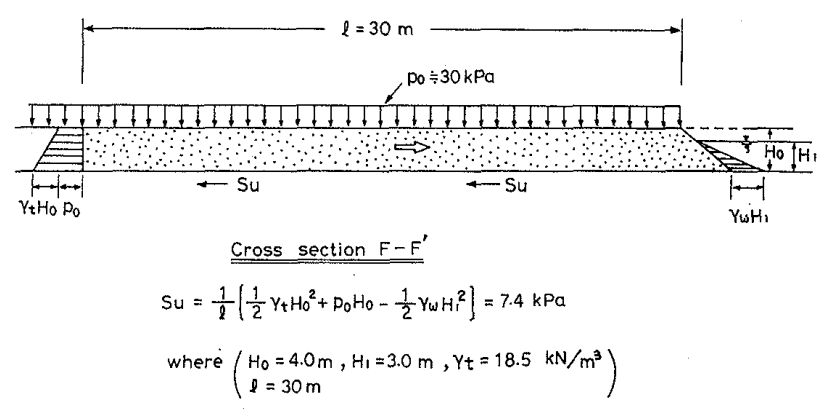

Fig. 31. Back-calculation scheme in cross section F-F'

the ground disruption due to the lateral spreading was pronouncedly observed along the riverside. In the area of Pogo Chico, three Swedish cone tests were performed in an alignment across section F-F' shown in Fig. 19. Approximate feature of the lateral flow near the riverside is shown in Fig. 29. The soil profile within the cross section F-F' obtained by the Swedish cone tests is displayed in Fig. 30, where a sliding plane is shown to run through a weak zone in the sand deposit beneath the silty surface layer. The back-calculation was made for a sliding soil mass as illustrated in Fig. 31, with the result that the residual strength is $S u=7.4 \mathrm{kPa}$.

\section{RESIDUAL STRENGTH VERSUS CONE PENETRATION RESISTANCE}

For several sites of failures caused by recent earthquakes where either Dutch cone or Swedish cone test data are available, a series of back-analyses was performed, and an empirical correlation was established between the residual strength and qc-value obtained from the Dutch cone penetration tests (Ishihara et al., 1990). The investigation on the flow failures of river banks in the city of Dagupan caused by the Luzon earthquake of 1990 provided three more data in addition to those from the cross sections, A-A', B-B' and C-C' (Ishihara et al., 1991).

In view of this, an attempt will be made to incorporate the outcome of the present study into the proposed framework of the data arrangements. To achieve this, the penetration resistance $W s w$ and $N s w$ obtained by the Swedish cone tests are converted to an equivalent $q_{c}$-value in the Dutch cone tests, by using the empirical formula in Eq. (1) and the relationship suggested by Robertson and Campanella (1985) for silty sands.

$$
q_{c}=3 N \text {. }
$$

It has been customary to modify the cone resistance to the $q_{\mathrm{cl}}$-value corresponding to an overburden pressure of $1 \mathrm{kgf} / \mathrm{cm}$ by using the relation

$$
q_{c 1}=\frac{1.7}{\sigma_{v}^{\prime}+0.7} \cdot q_{c}
$$

where $\sigma_{v}^{\prime}$ is the effective overburden pressure in $\mathrm{kgf} / \mathrm{cm}^{2}$. To allow for the effects of fines, the $q_{c 1}$-value is further modified by adding an increment, $\Delta q_{c 1}$, which is indicated in Fig. 32 as a function of fines content, $F_{\mathrm{c}}$. In obtaining this curve, the $q_{c 1}$-value corresponding to a back-calculated residual strength of $S u=0.1$ $\mathrm{kgf} / \mathrm{cm}^{2}$ was estimated to be about $8 \mathrm{kgf} / \mathrm{cm}^{2}$ for the $30 \%$ fines-containing sands from Metoki site and Chonan site (Ishihara et al., 1990). The value of $S u=0.1 \mathrm{kgf} / \mathrm{cm}^{2}$ was chosen because many of the back-analyses have yielded residual strength around this value. On the other hand, the value $N_{1}$ corresponding to the residual strength of $S u=0.1$ $\mathrm{kgf} / \mathrm{cm}^{2}$ was read off as being about 5 from the chart provided by Alba et al. (1988) which indicates the back-calculated residual strength as a function of SPT $N$-value. With recourse to the well-known relation, $q_{c 1} \fallingdotseq 4 N_{1}$ for clean sands, the $q_{c 1}$-value corresponding to $S u=0.1$ $\mathrm{kgf} / \mathrm{cm}^{2}$ is thus estimated to be approximately

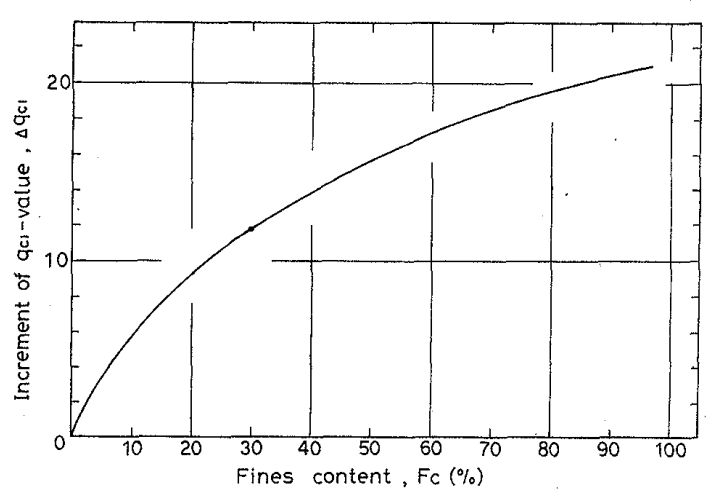

Fig. 32. Modification of $q_{c 1^{-}}$.value allowing for the effects of fines-content 


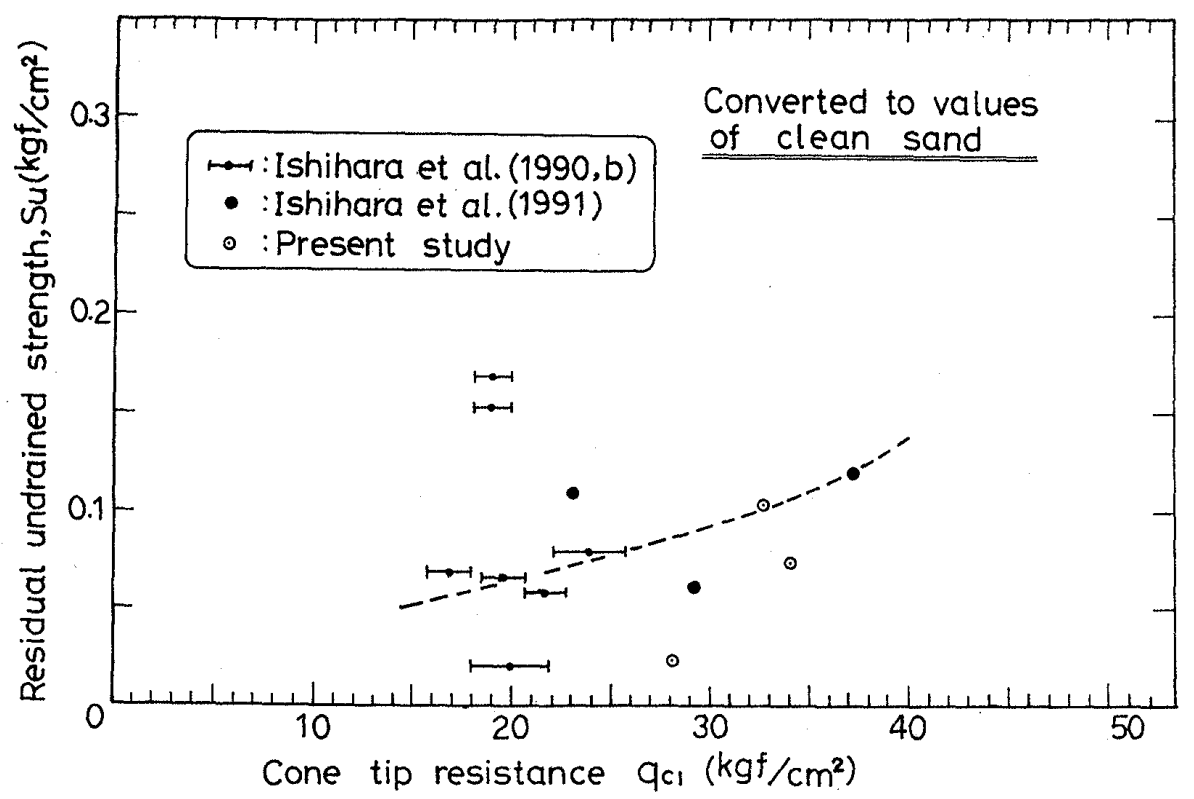

Fig. 33. Residual strength versus $q_{c 1}$-value for clean sands

20. Thus, for the inclusion of $30 \%$ fines, the $q_{c 1}$-value may be considered to decrease by an amount $\Delta q_{c 1}=20-8=12$ as compared to the $q_{c 1}$-value for clean sands. Based on the above consideration, the relationship between $\Delta q_{c 1}$ and fines content was established as approximately indicated in Fig. 32. It is to be noticed that, in the absence of any further convincing data, the curve shown in Fig. 32 should be regarded approximate and tentative. Using this relation, the $q_{c 1}$-value obtained along the assumed sliding plane at the cross sections D$\mathrm{D}^{\prime}, \mathrm{E}-\mathrm{E}^{\prime}$ and $\mathrm{F}-\mathrm{F}^{\prime}$ were modified by taking the fines content to be about $20 \%$. The value of $q_{\mathrm{c} 1}$ thus modified is plotted in the abscissa of the diagram in Fig. 33, together with the backcalculated value of residual strength plotted in the ordinate. The data points from the previous studies are also indicated in this figure. The average curve shown in Fig. 33 would provide a reasonably defined correlation between the residual strength and $q_{c 1^{-}}$ value which might be used for practical purposes.

\section{CONCLUSIONS}

General features of geotechnical damage during the 1990 July 16 Luzon earthquake,
Philippines were introduced with primary emphasis on the liquefaction-induced ground disruption in the city of Dagupan. The results of liquefaction analyses based on SPT-data showed that the sand deposits at depths between $2 \mathrm{~m}$ and $10 \mathrm{~m}$, formed by natural burial of old river channels or by sedimentation in the point bar area, were generic causes for developing liquefaction and associated damage. By identifying the unliquefiable surface mantle layer from the liquefied sand deposits underneath, a relationship between the thickness of the surface layer and that of the liquefied layer was established which can or can not bring about the surface manifestation of the disastrous consequence of liquefaction. This relationship was sought by analyzing the Swedish cone test data as well as the data of SPT. Both data sets show the same relationship to be valid.

The lateral spreads of the ground due to flow slide in the riverside area were another conspicuous feature of the damage caused by the liquefaction. Following the analyses described in the previous paper, three additional cross sections were taken up for the analysis of back-calculation to estimate values of the residual strength. The residual strength thus obtained was plotted against the equivalent 
$q_{\mathrm{c} 1}$-value in the Dutch cone penetration tests. Although there is some scatter the results showed a general tendency to agree with similar plots made previously from other data sets.

\section{ACKNOWLEDGMENTS}

In conducting Swedish cone penetration tests, the cooperation by Mr. K. Sakai of Kisojiban Consultants Co. was very helpful. Mr. Y. Hosoya of Kawasaki Steal Co. in Manila kindly made all arrangements necessary for conducting the comparative tests of SPT in the city of Dagupan. Mr. R. Orense, graduate student of the University of Tokyo helped to conduct the field studies in the devastated area. Dr. M. Gutierrez, research engineer at Norwegian Geotechnical Institute, provided some information on the soil profile in Dagupan. The authors wish to sincerely acknowledge the kind assistance and overall cooperation of these persons.

\section{REFERENCES}

1) Hamada, M. (1991): Report of Damage Reconnaissance for the 1990 Philippine, Luzon Earthquake., Association for Development of Earthquake Prediction (in Japanese).

2) Ishihara, K., Haeri, S. M., Monifar, A. A, Towhata, I. and Tsujino, S. (1992): "Geotechnical aspect of the June 21, 1990 Manjil Earthquake in Iran," Soils and Foundations, Vol. 32, No. 3, pp. 61-78.

3) Ishihara, K., Verdugo, R. and Acacio, A. A. (1991): "Characterization of cyclic behavior of sand and post-seismic stability analyses," Proc. 9th Asian Regional Conference on Soil Mechanics and Foundation Engineering, Vol. II, Bangkok, pp. 45-68.

4) Ishihara, K., Yasuda, S., and Yoshida, Y. (1990a): "Liquefaction-induced flow failure of embankments and residual strength of silty sands," Soils and Foundations, Vol. 30, No. 3, pp. 69-80.

5) Ishihara, K., Okusa, S., Oyagi, N. and Ischuk, A. (1990b): "Liquefaction-induced flow slide in the collapsible loess deposit in Soviet Tajik," Soils and Foundations, Vol. 30, No. 4, pp. 73-89.

6) Kisojiban Consultants (1990): Reconnaissance Report on the July 16, 1990 Luzon Earthquake (in Japanese).

7) Punongbayan, R. S. and Torres, R. C. (1991)" "Correlation of river channel reclamation and liquefaction damage of the 16 July, 1990 Luzon Earthquake in Dagupan city, Philippines," Philippine Institute of Volcanology and Seismology.

8) Punongbayan, R. S. and Umbal, J. V. (1991): "Overview and impacts of the July 16, 1990 Luzon Earthquake," Philippine Institute of Volcanology and Seismology.

9) Robertson, P. K. and Campanella, M. (1985): "Liquefaction potential of sands using the CPT," Journal of Geotechnical Engineering, ASCE, Vol. 111 , No. 3, pp. 384-403.

10) Seed, H. B. (1987): "Design problems in soil liquefaction," Journal of Geotechnical Engineering, ASCE, Vol. 113, No. 8, pp. 827-845.

11) De Alba, P. A., Seed H. B., Retamal, E. and Seed, R. B. (1988): "Analyses of dam failures in 1985 Chilean Earthquake," Journal of Geotechnical Engineering, ASCE, Vol. 114, No. 12, pp. 1414-1434.

12) Seed, R. B., Dickenson, S. E. and Idriss, I. M. (1991): "Principal geotechnical aspects of the 1989 Loma Prieta Earthquake,' Soils and Foundations, Vol. 31, No. 1. pp. 1-26.

13) Tokimatsu, K., Midorikawa. S., Kuwabara, S. and Abe, A. (1991): "Preliminary report on the geotechnical aspects of the Philippine Earthquake of July 16, 1990," Proc. 2nd International Conference on Recent Advances in Geotechnical Engineering and Soil Dynamics, St, Louis, U.S.A. Vol. 2, pp. 16931700.

14) Wakamatsu, K., Hamada, M., Tazoh, T., Yoshida, N. and Ando, T. (1991): "Liquefaction-induced ground failure during the 1990 Philippines Earthquake," Proc. 3rd Japan-U.S. Workshop on Earthquake Resistant Design of Lifeline Facilities and countermeasures for Soil Liquefaction, San Francisco, Technical Report NCEER-91-0001, pp. 23-37. 